\title{
The internal economics of a university - evidence from personnel data
}

\author{
Catherine Haeck and Frank Verboven*
}

May 2010

\begin{abstract}
Based on a rich personnel data set of a large university we find strong evidence for the existence of an internal labor market. First, the lowest academic rank is a strong port of entry and the highest rank is a port of exit. Second, wages do not follow external wage developments, since they follow administrative rules that have not been modified for a long time. We subsequently look at internal promotion dynamics to assess the relevance of alternative internal labor market theories. A unique feature of our data is that we have good measures of performance. Consistent with incentive theories of internal labor markets, research and teaching performance turn out to be crucial determinants of promotion dynamics. Learning theories of internal labor markets appear to have support when we do not account for observed performance, but the evidence becomes much weaker once we control for performance. Finally, we find that administrative rigidities play an important role in explaining promotion dynamics.
\end{abstract}

${ }^{*}$ Catherine Haeck: Catholic University of Leuven. Email: Catherine.Haeck@econ.kuleuven.be. Frank Verboven: Catholic University of Leuven and C.E.P.R. (London). Email: Frank.Verboven@econ.kuleuven.be. We thank Joep Konings, Paul Oyer, Frederic Warzynski and participants at several seminars for helpful comments. We gratefully ackowledge financial support from the Belgian Federal Science Policy Office (Interuniversity Attraction Poles P5/26). 


\section{Introduction}

During the last decades great progress has been realized in understanding how firms organize their employment relationships. Several theories of internal labor markets have been developed taking a variety of different perspectives: incentives under imperfect monitoring of effort, learning about ability, firm-specific human capital accumulation, administrative rigidities, etc. To establish the existence of internal labor markets, Doeringer and Piore (1971) identify two essential conditions: ports of entry at low job levels and ports of exit at high job levels in the hierarchy of the firm, and wage paths that move independently from external wages. Having established the existence of internal labor markets, one can test alternative theories of internal labor markets by looking at the pattern of promotion dynamics within the firm. For example, incentive theories predict that performance plays an important role in promotions, whereas learning theories predict dynamic patterns such as fast tracks and the late beginner property (late beginners who catch up promote more quickly in the future).

Recent empirical evidence from personnel data has shown support for both the existence of internal labor markets and the relevance of several alternative theories. In an important paper, Baker et al. (1994), henceforth BGH, collected a rich personnel data set of a single firm and documented several facts consistent with internal labor market theories, such as the presence of long careers with frequent one-step promotions. But they do not find strong evidence of ports of entry or exit, i.e. entry and exit at all job levels appears to be common. Subsequent work confirmed these findings, e.g. Treble et al. (2001) and Lazear and Oyer (2004). Other work introduced new and richer internal labor market theories to explain additional facts, e.g. Gibbons and Waldman (1999), DeVaro and Waldman (2006) and many others. A general conclusion that can be drawn from the recent empirical evidence is that (1) internal labor markets exist but typically not in the purest form of Doeringer and Piore (1971), and (2) no single theory can explain all facts relating to internal promotion dynamics.

In this paper we provide new evidence on the working of internal labor markets based on a unique and very rich new personnel data set. We observe the personnel records of all professors employed at a large European university during 1972-2007. This analysis is of interest for several reasons. First, the university we study has followed a set of administrative rules that is much simpler than the personnel policies in many other companies: professors can have only four possible ranks; they can be promoted to higher ranks in an annual "tournament"; and wages conditional on rank follow deterministic seniority rules. Current wage is therefore entirely determined by the starting rank, the starting seniority level and the 
speed of future promotions. The simplicity and clarity of the rules provide an ideal setting to test the relevance of alternative labor market theories.

Second, in contrast with most other empirical work, we have good information on performance (research and teaching). This does not only enable us to assess the relevance of performance-based incentive theories of promotion dynamics. It also allows us to see whether and to which extent learning theories of promotion dynamics, as documented in previous work, remain empirically relevant after accounting for observed performance.

A third reason for studying this data set is to investigate to which extent internal labor market theories also apply to universities. It is often believed that internal labor market theories have little relevance to universities as human capital is assumed to be general [see e.g. Lazear and Oyer (2004)]. ${ }^{1}$ But several studies have recognized the role of mobility costs at universities, so that human capital may also be firm-specific. ${ }^{2}$ Yet others would argue that (European) universities have rigid administrative rules with little leeway to follow personnel policies that are consistent with economic theories. Using our personnel data set, we are able to document to which extent economic theories of internal labor markets are relevant and to which extent administrative rigidities play a role.

Our main results can be summarized in two steps. First, we find strong evidence for the presence of an internal labor market at this university. The lowest academic rank is a strong port of entry, and in fact entry occurs at even earlier levels. The highest academic rank is an important port of exit, and if exit occurs before it is mainly because of retirement. Furthermore, wages are shielded from external wage evolutions since they are set according to deterministic rules which have not been modified for many years. These facts are consistent with Doeringer and Piore (1971) and Lazear and Oyer (2004) classification, and imply the presence of a strong internal labor market, in fact much stronger than documented in the earlier empirical work described above.

Second, having established the presence of an internal labor market, we assess the relevance of alternative theories by looking at the dynamics of long careers within the university. Consistent with incentive theories we find that observable performance plays an important role: the number of publications, the impact of these publications and the teaching load all

\footnotetext{
${ }^{1}$ For example, Lazear and Oyer (2004) write that "human capital in academics, particularly at the research end, is general, so movement into jobs even at high levels seems natural."

${ }^{2}$ For example, Ransom (1993) develops a model to explain that employees with high mobility costs will have high seniority yet low pay if monopsonistic employers can discriminate. He finds evidence that university professors are indeed paid less when they have higher seniority. However, Hallock (1995) obtains opposite empirical evidence based on data for one university (UMASS).

In a related sector (stock analysts), Groysberg et al. (2004) show the importance of various sources of mobility costs leading to firm-specific human capital (such as internal networks, teams, leadership), which can also be relevant to universities.
} 
affect the speed of promotions, though the policies differ to an important extent between the three main groups of the university (exact sciences, medical sciences and humanities). Furthermore, after controlling for observed performance, theories of learning about ability appear to play a less important role. If we do not control for observed performance, we find evidence of fast tracks and the late beginner property as predicted by learning theories: professors have a higher promotion probability if they were quickly promoted into previous ranks and especially if they were quickly promoted into their current rank. However, once we control for research and teaching performance, the evidence for learning theories weakens: the estimated magnitude of fast track effects becomes smaller but is still significant, and the evidence for the late beginner property becomes weaker. We used a discrete-time promotion hazard rate model of absolute performance evaluation to establish these findings and our results are robust when we use a simple tournament model of relative performance evaluation. $^{3}$

In sum, we find much stronger evidence for the presence of an internal labor market in the university we have analyzed than in the private companies that were analyzed in other studies using personnel data. The evidence on promotion dynamics is consistent with performance-based incentive theories, whereas learning theories play a less important role. However, given that the university has been following its administrative rules quite rigidly for a long time, it is not possible to rule out inefficiencies in personnel policy. Since the university landscape is changing rapidly, several rules may be in need of change, not only at this university but also at many other European universities with similar administrative rules and policies.

More concrete policy recommendations for university reform are, however, beyond the scope of this paper. Further comparative analysis on other European and U.S. universities would first be required. In this respect, it is useful to point out the results of two interesting recent papers on university career dynamics (based on less detailed data sets for multiple universities instead of the richer data set on a single university we use). Using a sample of top 1000 economists, Coupé et al. (2006) find support for both incentive and learning theories, but no evidence of internal labor markets. Oyer (2008) shows how updated expectations about economists' ability during the first career period may affect second period placement, consistent with the learning model.

The outline of the paper is as follows: Section 2 provides theoretical background and Section 3 presents the data set. After introducing the university's personnel policies, Section

\footnotetext{
${ }^{3}$ Our finding that the evidence for the learning model becomes weaker once we incorporate performance measures is in the same spirit as Kahn and Lange (2009), although they use a different approach. They find that wage dynamics is predominantly explained by time-varying productivity rather than by learning.
} 
4 documents the existence of internal labor markets: strong ports of entry and exit and the implementation of wage rules independent of external market developments. Section 5 then looks at the dynamics of careers to assess the relevance of specific internal labor market theories. Because we obtain many different empirical results, we will summarize our main empirical findings in various Observations.

\section{Theoretical background}

We provide a short review of theoretical work in personnel economics, focusing on the literature that is most relevant for our own empirical analysis. For more detailed overviews of the literature we refer to Waldman (2007) and Lazear and Oyer (2007).

Suppose that firms have perfect information about their workers' efforts and abilities, and that human capital is general so that workers' productivity does not depend on the firm where the worker is employed. Under these conditions, external labor markets can allocate labor efficiently. Workers can be paid on the spot market according to their marginal productivity. There would be no need for long-term promotion schemes to encourage effort or uncover ability, nor for long-term contracts to protect relation-specific investments in human capital. There would be no ports of entry and exit at firms, so that careers would not necessarily be long-term; and to the extent careers within the firm are long term, wages would be strongly correlated with external wages.

Theories of internal labor markets depart from the traditional competitive labor markets because of two main features. First, within a firm's hierarchy there may be ports of entry at low job levels and ports of exit at high levels. Second, wages within a firm may move more or less independently of external wages. These two conditions for the presence of an internal labor market were first identified by Doeringer and Piore (1971), and they have subsequently been investigated in other empirical work. While these conditions establish the presence of internal labor markets, they do not say which theory of the internal labor market is most relevant. To test the relevance of specific theories, one can look at testable predictions about internal promotion dynamics of alternative theories. We will distinguish between three main classes of internal labor market theories and their empirical predictions.

A first class of relevant models focuses on the provision of optimal incentives under imperfect observability of effort. Holmstrom (1979) model starts from the basic trade-off between insurance and incentives. The model predicts that workers receive part of their pay as a fixed amount and part of their pay according to their realized performance. Lazear and Rosen (1981) propose a tournament theory of promotions. Effort is unobservable so that good performance may be either due to high effort or good luck. Workers start at low levels 
and low wages and will be promoted to higher levels if they perform better than other workers at the same level. The spread between wages at two different levels is the prize of winning the tournament and serves to induce an optimal effort level. The optimal spread will be higher in uncertain environments where luck is important. Tournaments create potentially great informational advantages compared with other work incentive contracts, since it is only necessary to provide an ordinal ranking of the employees. Tournament theory has been extended in many directions. For example, Nalebuff and Stiglitz (1983) consider riskaverse employees and Rosen (1986) considers multiple elimination tournaments, showing the importance of concentrating prizes among few participants at each round.

A second class of models focuses on learning about workers' productivity or ability. Harris and Holstrom (1982) develop a model of symmetric learning, where both firms and workers have little information about the workers' ability at the start of a relationship and gradually learn about ability by observing output over time. Firms are risk neutral and workers are risk averse about how beliefs regarding their ability will evolve. The model predicts a downward rigid real wage path to partially insure workers. It also predicts fast tracks, i.e. employees who were promoted more quickly from level 1 to level 2 are more likely to be promoted quickly to level $3 .{ }^{4}$ Chiappori et al. (1999) derive another interesting prediction from the learning model: the late-beginner property. Consider two workers A and B who were promoted equally quickly from level 1 to level 3, but worker A was promoted more quickly to level 2 than worker B. Hence, as shown in Figure 1, worker A was an early starter and $\mathrm{B}$ was a late beginner who was able to catch up. The learning model predicts that the late beginner B is more likely to be promoted to level 4. Intuitively, the late beginner had bad luck at the start. From the fact that he was still able to catch up one can infer that his average performance between level 1 and level 3 was higher, so that his perceived future ability is higher. In Section 5, where we conduct our empirical work, we show that the fast track and late-beginner property can be combined to give the following equivalent predictions: the speed of the most recent promotion (to level 3) has a positive impact on the probability of a new promotion (to level 4), and this impact is stronger than the impact of the speed of older promotions (to level 2).

A third class of models that predict ports of entry and wages shielded from external wages looks at models with firm-specific human capital [Becker (1962)]..$^{5}$ If workers accumulate firm-specific human capital, a situation of bilateral monopoly arises, so that workers' wages

\footnotetext{
${ }^{4}$ Farber and Gibbons (1996) develop a symmetric and public learning model, without long-term contracting. They obtain somewhat different testable predictions about wage dynamics, for example unobserved ability should increasingly be correlated with wages as experience increases.

${ }^{5}$ Gibbons and Waldman (1999) develop a rich model that incorporates both human capital accumulation, learning and job assignment. The model is consistent with many empirical findings on promotion dynamics.
} 
do not need to correspond to competitive wages. Workers may be expected to enter at low levels and move up when they have acquired more human capital inside the firm. A specific prediction of these models is that external entrants into a job level may perform worse than internally promoted workers and that the variance in performance is higher.

\section{The data set}

The university we study is a large European university, currently ranked in the top 100 of the QS World University Rankings. Our data set consists of the personnel records of all professors employed over a 35 years period from 1972 to 2007. There is a small but growing empirical literature using personnel records of individual firms at this level of detail. Lazear (1990) observes a large firm for thirteen years. Baker et al. (1994) follow a medium-sized U.S. services firm during the period 1969-1988. Treble et al. (2001) observe a large British financial services firm during 1989-1997. Chiappori et al. (1999) study a French state-owned company during the period 1960-1982. Lazear and Oyer (2004) collected a standardized data set of personnel records of multiple unionized Swedish firms.

Our own data set is unique because it covers a very long time period, it considers a university where personnel rules are particularly clear and simple, and it contains information on the key performance variables of employees: research and teaching. We first provide an overview of the data set and then discuss summary statistics.

\subsection{Overview}

Figure 2 describes the evolution of the number of professors in the university, including both the total number and the numbers broken down by the three university groups: medical sciences, exact sciences and humanities (including social sciences). During our sample period 1972-2007, the number of professors nearly tripled from approximately 500 to almost 1500. The growth in employment took place in all three groups, but it was more pronounced in medical and exact sciences than in humanities. Although the growth in employment has been considerable, it does not match the even greater growth in student numbers. Between 19922007 the number of students increased by $41 \%$ (from 26,087 to 36,768), while the number of professors increased by only $27 \%$ (from 1,144 to 1,456 ).

The personnel data set records the employment information of all professors at the start of each academic year (October 1st). Professors may have four possible ranks, ranging from assistant professor to full professor, and they may either have an untenured or a tenured status. We observe 2,691 different professors at some point in time over 1972-2007. Over 
this period we have a total of 36,284 employee-year records, yielding an average number of professors per year of 1,037 and an average observed employment duration in professorship of 13.5 years. Many professors were already employed at the university before entering professorship, as a pre-doctoral and/or post-doctoral employee. The average observed total employment duration at the university is therefore longer and amounts to 18 years.

The personnel records contain the following information for each professor: anonymous identification code, age, sex, nationality, current academic year, affiliation within the organization (university group, faculty, department), academic rank, tenure status, part-time appointment status, seniority and employment history (previous academic ranks, pre-doctoral and post-doctoral positions, year and location of Ph.D., age at entry).

We matched the personnel data set with two additional data sets on performance provided by the university. The first additional data set includes teaching load and selected management duties (such as dean or department head). This information is recorded at the end of the academic year. The second additional data set contains two measures of research performance: number of publications and average impact factor per year. We have three different sources. First, we have the Science Citation Index Expanded (SCIE) measures for the period 1991-2006. SCIE primarily accounts for publications in exact sciences and medical sciences. Second, we have the Social Sciences Citation Index (SSCI) measures for 1997-2006. The SSCI measures combine publications from both the Social Science Citation Index and the Arts and Humanities Citation Index (AHCI), but we will refer to it as SSCI for simplicity. SSCI mainly accounts for publications in psychology and economics, and not so much in other fields such as literature and philosophy, where professors publish elsewhere ${ }^{6}$. Third, we have the Proceedings measure for 1996-2006. Proceedings counts the number of publications related to conferences (ISI Proceedings) and mainly accounts for publications in engineering (exact sciences) with a bias towards American conferences. All research performance measures are calculated based on the publication date from January to December.

Table 1 provides a definition of the main variables.

\subsection{Summary statistics}

Table 2 shows the number of observations (professor-years) and the averages of our main variables, for the entire period 1972-2007 and the subperiod 1991-2007. Table 2 shows that there is complete or almost complete information since 1972 for the most commonly used personnel variables: the number of observations is equal or close to 36,284 for the variables

\footnotetext{
${ }^{6}$ SSCI has been corrected to ensure that publications counted in SCIE are not also counted in SSCI. The impact factor in both SSCI and SCIE is based on the number of citations within SSCI and SCIE. If the paper is cited elsewhere it is not counted.
} 
age, sex, nationality, group affiliation and most contract characteristics (dummy variables for rank, part-time appointment and tenure status).

There is, however, less complete information for the teaching and research performance variables (which come from different data sets as discussed above). First, information on teaching load and management tasks is only available since 1980. Second, information on publication performance (number of publications and average impact factor) is only available since 1991 for SCIE data, and since 1997 for SSCI and 1996 for ISI Proceedings. Finally, there is also a non-negligible number of missing observations for Ph.D. location and we only observe seniority on a systematic basis since 1999. But if we limit our attention to the period 1991-2007, the information is quite complete for most variables. For this reason, and the fact that there was a change in personnel policy at the beginning of the 1990 (as discussed below), we will concentrate part of our empirical analysis on the period 1991-2007.

It is instructive to look at the variable means in Table 2. For example, only $9 \%$ of the professors were women over the entire period 1972-2007, though the fraction was higher at 13\% during the period 1991-2007 (compared with about 3\% before 1991). A professor's average age was more or less constant at 49 years over all periods. Only a small minority of professors has a foreign nationality (less than 4\%) and a Ph.D. from another university (less than 14\%). The entrant type variables show that only $18 \%$ of the professor-years were external hires, i.e. they did not have an employment history at the university prior to entering in one of the academic ranks. This fraction is even lower for the period since 1991 (15\%). Similarly, only $6 \%$ of the professor-years are entrants in rank 2 and only $4 \%$ are entrants in rank 3; the vast majority of observations are entrants from the lowest rank 1.

Table 2 also summarizes several aspects of the employment contract. Since 1991 professors are spread more or less evenly across the three university groups, with $34 \%$ of the professor-years in humanities, $35 \%$ in medical sciences and $30 \%$ in exact sciences. This used to be different in the earlier decades, when professors in humanities outnumbered professors in other university groups (with about $46 \%$ of the positions during 1972-1979 and $45 \%$ of the positions during 1980-1990). Up to $41 \%$ of the professor-years are in the highest of four possible academic ranks. However this share has decreased in more recent years, with $33 \%$ in the highest rank 4 for the period 1991-2007. The large majority of professor-years is tenured (84\%), and this is true for both the entire period and the period since 1991. A particular feature of the university is the number of part-time appointments. About $30 \%$ of the professor-year observations refer to part-time appointments.

The bottom part of Table 2 summarizes performance information. The average teaching load is 5.1 week-hours over the entire period and 4.6 week-hours during 1991-2007, where one week-hour roughly corresponds to $26-30$ hours of teaching. The number of management 
duties has been stable at 0.3 per professor. The average number of publications (cumulative annual average over 5 years) was 2.5 in SCIE, 0.1 in SSCI and 0.3 in Proceedings. But these averages hide important performance differences between the three main university groups. Table 3 shows that teaching load has been comparable for professors in exact sciences and humanities (about 5 week-hours), but considerably lower in medical sciences (3.4 weekhours). The annual number of SCIE publications is highest in medical sciences (4.5) and exact sciences (3.1), while it is small in humanities. Conversely, the number of publications in SSCI is highest in humanities (0.3), but there is a high standard deviation (0.6), in part because these publications are only relevant for social science fields and much less for other fields such as literature or philosophy.

A separate Appendix provides additional summary statistics of the data set. First, it presents a more detailed version of Table 2, with additional subperiods 1972-1979 and 19801990. Second, it shows several figures documenting the evolution of the percentage of women, foreigners and outside PhDs since 1972; the evolution of teaching load since 1980; and the evolution of research performance since 1991.

\section{The university as an internal labor market}

In this section we show that Doeringer and Piore's (1971) two conditions for an internal labor market are satisfied to a much stronger degree for this university than for firms in other empirical studies. First, we describe the university's hiring and promotion policy. We establish the presence of a strong port of entry at the lowest rank and a somewhat less strong port of exit at the highest rank, implying long internal careers. Next, we discuss the university's wage policy. We find that wages conditional on rank are largely deterministic and thus independent from external influences.

In the next section we will examine more closely the dynamics of long careers within the university to assess the relevance of alternative specific theories of internal labor markets. To facilitate the reading, we will summarize the main results of these sections in various Observations.

\subsection{Hiring and promotion policy}

\subsubsection{Administrative rules}

The university's personnel policy follows a set of administrative rules that are partly based on a government decree and partly based on internal rules. Professors may be appointed in one of four possible academic ranks, ranging from rank 1 (assistant professor), ranks 2 and 
3 (associate professor) to rank 4 (full professor). They may either have an untenured status or a tenured status (permanent contract). In recent years untenured positions typically resulted in a tenure decision after three years. Professors may have a part-time or a full-time appointment. If they have a full-time appointment, they are entitled to become part-time on a temporary basis for a total of eight years during their career.

The government restricts the maximum number of professors that can be hired relative to the number of other employees (technical staff and Ph.D. students). This has implications for the university's hiring and promotion policies. Every year the university decides on the number of new academic openings that may be filled, with detailed specifications per opening. Furthermore, every year the university makes available a maximum number of promotions per academic rank and per university group. Promotions are granted through an annual "tournament". Applications for promotion are reviewed based on three main performance criteria: research, teaching and management duties. The ranking of candidates is initially made at the faculty level, and subsequently aggregated to the level of the three university groups. University rules stipulate that professors can typically only be promoted one rank higher, and should stay at least two/three full years within a rank before being eligible to apply for a next promotion. Promotion decisions become effective on October 1st of each academic year.

\subsubsection{Structure and stability of the hierarchy}

Previous personnel studies looked at private companies and stressed that the structure of the hierarchy looks complicated at first, but ultimately reduces to a fairly simple structure with between 4 to 8 job ranks [see for example BGH and Treble et al. (2001)]. In the university we study, the hierarchy is even simpler as there are only four academic ranks. Figure 3 shows the structure of the hierarchy at several points in time. Unlike other studies, it suggests that there was no real "structural stability" in the hierarchy. This is however due to a major reform in the ranking system in 1991. Before 1991 (top panel) rank 2 did not yet exist, and most professors were either in the lowest rank 1 or in the highest rank 4. The reform in 1991 split rank 1 into two ranks, rank 1 and rank 2. This reform led to a more even distribution of professors across the four ranks with a slightly inverse pyramid structure, as illustrated by the years 1993 and 2003. The relative number of professors remained stable for the period 1993 to 2007 , with only a tendency for rank 3 to gain in relative importance. ${ }^{7}$

We can summarize these findings as follows:

\footnotetext{
${ }^{7}$ In 2007 , the last year of our study, the hierarchy had an inverse pyramid structure that was extremely similar to 2003.
} 
Observation 1 The university's hierarchy is simple and is relatively stable within the subperiods 1972-1990 and 1991-200\%.

We focus our subsequent discussion on the subperiod 1991-2007. ${ }^{8}$ This is not only because this period is stable relative to the period before the reform in the ranking system but also because we have more information on performance, as discussed before. Nevertheless, where applicable, we also provide more detailed results on other subperiods in the separate Appendix.

\subsubsection{Ports of entry and exit, and long-term careers}

Insights into the hiring and promotion policies are obtained from looking at the number of annual job transitions. Extending BGH's Table I, we present a job transition matrix for the period 1991-2007 in Table 4.

Row 4 of the transition matrix (Total Entry) shows that most entry occurs in the lowest rank: there were 948 entrants in rank 1. Entry in rank 2 was considerably less important and entry in rank 3 and 4 was very rare. Rows 1 to 3 of the transition matrix distinguish between three types of entry. "Internal entry" refers to entrants into the professor ranks by individuals who previously held a non-professor position at the same university (Ph.D. students, post-doctoral researchers or visiting lecturers). "Delayed internal entry" is similar, but with the qualification that the individual was employed elsewhere for an intermediate period. Finally, "external entry" is a transition into professorship by an individual who was never employed at the university before. Most entry is internal: there are 767 internal entrants (into any rank), compared to 238 delayed internal entrants and only 260 external entrants. External entry is comparatively more important in the highest ranks 3 and 4 , but it is rare in absolute terms.

In sum, we have:

Observation 2 The lowest rank 1 is a strong port of entry. In fact, the port of entry mostly takes place prior to professorship.

It is interesting to contrast this with Coupé et al. (2006), who find evidence of upward mobility (to higher ranked universities) in response to past performance. This may indicate that ports of entry are less important in U.S. than in European universities. Alternatively, their different finding may be due to the fact that they focus on a sample of top economists,

\footnotetext{
${ }^{8}$ Our results are very similar for alternative subperiods, e.g. 1993-2007 where we exclude the first years after the reform.
} 
whereas we consider the complete personnel records of a university. Further research on U.S. and European universities would be interesting to shed further light on this.

Columns 5 and 6 of Table 4 show exits from the various ranks. There is a small group of professors who temporarily exit (Temp Out column) to come back later in one of the four ranks (Temp Out row). Permanent exit (Total Exit column) most frequently occurs at the highest rank 4 (386 out of 827 cases), but there has also been a non-negligible number of exits from the other ranks $(151+165+125=441$ cases in total). To further understand the sources of exit, columns 7 to 9 break the exit down in three possibilities. "Early exit" is exit before the age of 60, "early retirement" is between 60 and 65, and retirement is at the age of 65 . Other work has not taken into account that exit may be due to retirement. The table shows that most exit is through retirement or early retirement $(447+171=618$ out of 827 cases) and much less because of early exit (209 cases). Exit from rank 1 is mainly early exit because tenure was not given (103 out of 151 cases), but exit from ranks 2, 3 and 4 are mainly because of retirement or early retirement.

In sum, we can conclude:

Observation 3 The highest rank 4 is an important port of exit. If exit occurs at the lower ranks 2 and 3, it is mainly because retirement age has already been reached.

Observations 2 and 3 are in stark contrast with other personnel studies, such as Lazear (1990), BGH or Treble et al. (2001) who observe considerably more "late entry" and "early exit". Furthermore, we find that entry in fact occurs at even earlier levels than rank 1 (a finding that is not applicable to these other studies) and we are able to distinguish between the sources of exit (true early exit versus retirement).

The intersection of rows 5-8 and columns 1-4 shows the career transitions of professors employed in one of the four academic ranks. Non-promotions or stays are on the "diagonal" (starting from the fifth row onwards), promotions are to the right of this diagonal and demotions are to the left. Stays are most commonly observed. For example, there are 3,818 cases of professors staying in rank 1 at some year. Promotions are almost always one-rank promotions, e.g. 616 promotions from rank 1 to 2 . There were only 19 promotions of two ranks. Demotions are essentially non-existent (only 1 case).

Recalling our earlier discussion on the promotion rules, we can conclude:

Observation 4 The administrative promotion rules are largely followed; almost all promotions are one-step promotions. 
Table 5 gives further insights into entry, exit and career characteristics, following a structure similar to BGH's Table II on career and rank characteristics.

The top panel of Table 5 considers all professor-years between 1991 and 2006 to focus on entry and exit patterns. The bottom panel limits attention to only the professors that were hired between 1991 and 1999. Following BGH, this enables us to follow the length and number of ranks in their subsequent careers and avoid censoring problems when we would also include the 2000-2007 hires.

The top panel confirms our finding that rank 1 is a strong port of entry. Only $21.5 \%$ of those entering rank 2 were newly hired rather than promoted from rank 1 . New hires are even less important than promotions at ranks 3 and 4 (7.8\% and $6.8 \%$ respectively). ${ }^{9}$ Furthermore, among the newly hired professors the large majority are internal hires, i.e. with a prior employment history at the university ("internal entrants" or "delayed internal entrants" in our earlier terminology). Up to $84.5 \%$ of rank 1 new hires were internal hires and similar large proportions apply to rank 2 hires. In sum, these findings confirm Observation 2 that there is a strong port of entry at the lowest rank (i.e. rank 1), and in fact at earlier points before entering professorship.

The top part of Table 5 also confirms our earlier Observation 3 that the highest rank is a relatively strong port of exit, and that the majority of exits at ranks 2 to 4 is due to retirement. Only at rank 1 are there more early exits than retirements (because of non-tenure decisions).

The bottom panel of Table 5 shows how careers of professors hired between 1991-1999 developed during the entire period 1991-2007. Careers last very long: over $84 \%$ of professors hired in rank 1 and $81 \%$ of professors hired in rank 2 had careers of at least eight years. Careers of professors hired in the higher ranks ( 3 and 4 ) tend to be somewhat shorter: $58 \%$ of rank 3 hires and $69 \%$ of rank 4 hires are still at the university after eight years. This is largely due to the higher age at which they enter professorship. Furthermore, most entrants into professorship have a long prior employment history at the university (e.g. Ph.D. student or postdoctoral researcher), about 8 years on average. In sum, careers tend to be substantially longer than documented in BGH's comparable Table II.

Careers are not only very long, they also show steady progress. Of the professors with lengthy careers (more than 8 years), only $18 \%$ of the rank 1 hires did not promote to a higher rank; $28 \%$ promoted one rank, $26 \%$ two ranks and the remaining $29 \%$ even three ranks up to the highest rank. The majority of rank 2 or 3 professors also promoted to the highest rank. We can summarize these findings as follows.

\footnotetext{
${ }^{9}$ The percentages of newly hired are in line with the 1991-2007 transition matrix (Table 4) but are not exactly the same because the period is slightly different.
} 
Observation 5 Careers within the university are very long, and they show steady progress to higher ranks.

\subsection{Wage policy}

We now discuss the wage policy of the university. As noted by Aghion et al. (2007), there is no wage autonomy in many European universities, including Belgium, Germany, Ireland, Italy, Spain and Switzerland. In the university we study wages also follow deterministic rules. The current system has not been modified since 1991 and it includes an automatic wage indexation to compensate for inflation.

Wages are based on the professor's current academic rank and his seniority within the rank. Each of the four academic ranks has a separate salary scale. Every year of employment results in an additional seniority step. If a cycle of three steps is completed, the salary increases to a new level and a new three-step cycle begins. When a professor is promoted to a higher academic rank, he receives a wage according to the new salary scale. The number of seniority steps in his new rank will be the lowest number such that (1) the wage is not lower than without the promotion and (2) the position within the three-step cycle is maintained. For example, a professor who is currently in the second year of a three-step cycle will upon promotion move to the third year of the cycle in the new rank that gives at least the same wage.

These seniority rules imply that a professor's wage path essentially depends on the following elements: the rank at entry, the number of seniority steps negotiated at entry, and the timing of subsequent promotions. Figure 4 shows the salary scales for the four ranks. The salary of a professor in rank 1 with zero years of seniority is normalized to 100 . One can clearly see how wages increase after a three-year cycle is completed. To illustrate how promotion affects wages, the bold line shows the salary path of a professor who enters in rank 1 with zero years of seniority and who is promoted to the next rank after five years. It would take this professor 27 years for the (real) wage to increase from 100 to 230 .

In sum, the wage path within a rank and between ranks is consistent with Gibbons and Waldman's (1999) summary:

Observation 6 Wage increases upon promotion are large, but they are small relative to long-term wage increases within a rank.

One may wonder whether the university strictly applies these administrative rules in practice, or whether it has discretion by setting higher or lower seniority steps than implied 
by the rules. Table 6 addresses this question. It compares a professor's actual seniority step with the seniority step he would have obtained if the administrative rules were strictly followed.

The top panel shows the results of this comparison for professors in years when they did not receive a promotion to a higher rank. This shows that the professor's seniority follows the administrative rules in $93.3 \%$ of the cases. Upward or downward deviations by more than 2 seniority steps are very rare ( $0.2 \%$ of all cases, not shown in the table). Most of the 1-step or 2-step deviations are upward and occur in rank 3.

The bottom panel of Table 6 shows the comparison for professors in years when they were promoted to a higher rank. This shows that the administrative rules are respected in a much smaller fraction of only $50.4 \%$ of the cases. Nevertheless, upward or downward promotions by more than 2 seniority steps are still uncommon ( $2 \%$ of all cases). Quite remarkably, deviations from administrative rules are most commonly downward deviations (by 1 or 2 steps). This may indicate that time of promotion is used to adjust an initially "incorrect" seniority level. More importantly, cases where professors get more than the administrative rules are rare. These findings indicate that the university follows the seniority rules very closely. Since the system has not been modified since 1991, this indicates that wages move independently from external wages.

We can summarize this discussion into the following counterpart of Observation 4, which relates to promotion policies.

Observation 7 The administrative wage policies are largely followed: seniority steps are mostly at the right level or deviate by only a small amount. Since the policies have been in place for a long time, this implies wages are shielded from the external wage evolution.

\section{Internal career dynamics}

The evidence in the previous section indicates that Doeringer and Piore's two main conditions for internal labor markets are satisfied: the existence of strong ports of entry and exit, and wages that follow rules independent of external market developments. In this section we now go deeper into the specific career dynamics of professors to assess which particular internal labor market theories are most relevant. We first follow BGH and present descriptive nonparametric promotion hazard rates conditional on the number of years in previous ranks. We subsequently extend this analysis to estimate a semi-parametric hazard rate model of promotion. This enables us to test predictions of the learning model of promotions and 
incorporate the importance of observed performance.

As in the previous section, we will again summarize our main findings in various Observations. While the non-parametric promotion hazard rates of section 5.1 already suggest some first tendencies, we postpone the main Observations until we have estimated the complete hazard rate model in section 5.3.

\subsection{Promotion hazard rates}

The promotion hazard rate is the probability of promotion conditional on not being promoted before. How does the promotion hazard rate evolve over time? Does it show an increasing, constant or decreasing pattern? Furthermore, how does the promotion rate depend on the speed of promotions into previous ranks? Are there fast tracks, i.e. are promotion rates higher for individuals who were promoted quickly to a previous rank? This may be expected if there is learning about ability. But if firm-specific human capital accumulation rather than learning is important, the opposite may hold: professors who were promoted quickly to a previous rank accumulated less human capital and would therefore have a lower probability to be promoted quickly again.

Table 7 presents the promotion hazard rates of professors currently in rank 2 (top panel) or rank 3 (bottom panel) ${ }^{10}$. The promotion hazard rates are shown conditional on the duration in the current rank (columns) and on the duration in the previous rank (rows). The final row of each panel ("All") shows the traditional promotion rates, unconditional on the duration in the previous rank. The table corresponds to BGH's Table IV, but we only present the promotion rates and not the exit rates, since these are considerably smaller (as documented earlier) and show little variation.

Consider professors who are currently in rank 2 (top panel of Table 7). The promotion rates unconditional on duration in previous rank (final row) are very low for the first two years in the current rank $(0 \%$ and $3 \%)$. This reflects the university's administrative rules stipulating that promotion is not possible during the first two years. The promotion rates increase sharply during the next two years (to 25\% and 26\%) and gradually decline afterwards. This inverse U-shaped pattern suggests that the administrative rule not to promote in the first two years upon a previous promotion is an effective constraint on the university's performance-based personnel policy. We will confirm this finding below where we include

\footnotetext{
${ }^{10}$ In this section we restrict our attention to professors whose career was not impacted by the 1991 ranking system reform (i.e. introduction of rank 2). This essentially means we exclude professors promoted to rank 3 and 4 prior to the reform and professors promoted to rank 2 in the first year of the reform. So we effectively exclude all observations for professors whose time spent in rank 1 and/or rank 2 may be biased due to the reform.
} 
performance measures into the model.

Reading the top panel of Table 7 down the columns indicates that current promotion rates tend to be highest for professors who stay 3 years in the previous rank: these are the professors who were promoted to the previous rank as soon as they became eligible according to the administrative restrictions. The promotions rates subsequently tend to decrease as the duration in the previous rank increases. This is a first evidence of the existence of fast tracks. For example, consider the third column with professors who are 3 years in the current rank. The average hazard rate of promotion of these professors is $25 \%$. The hazard rate of the subset of professors who stayed 3 years in the previous rank is $41 \%$, much higher than the average. It is $37 \%$ for professors who stayed 4 years in the previous rank and shows a further tendency to decline for professors who stayed even longer in the previous rank. The fourth column confirms this pattern: the promotion rate is highest for professors who stayed 3 years in the previous rank $(39 \%)$ and it subsequently declines. ${ }^{11}$

The bottom panel reveals similar patterns for professors currently in rank 3. First, the hazard rate is essentially zero during the first two years, it sharply increases to $30 \%$ in the next year and it gradually declines. Second, the columns show evidence of fast tracks, with the highest promotion rates for professors who stayed 2-3 years in the previous rank and lower rates for professors with slower earlier progress.

We can summarize these preliminary descriptive findings on promotion dynamics as follows. First, the inverse U-shaped pattern of promotion rates (initially very low, then sharply increasing and subsequently decreasing) suggests the importance of institutional constraints in granting promotion during the first years. Second, the fact that promotion rates decline with duration in previous rank suggests some first evidence of fast tracks. This is consistent with learning models of internal labor markets and not with models of firm-specific human capital accumulation, according to which fast progress in previous rank indicates little human capital accumulation and thus a low subsequent promotion probability.

The promotion hazard rate results in Table 7 are only preliminary evidence. The patterns are not always that clear for cases with a limited number of observations. Furthermore, Table 7 only showed dependence of promotion rates on duration in current and previous ranks. But learning models also make predictions about the dependence on duration in earlier ranks, i.e. Chiappori et al. (1999)'s late-beginner property. Finally, the results in Table 7 did not control for observed performance determinants of promotion. To take these elements into account, the next subsection extends BGH's analysis and estimates a semi-parametric hazard rate model for promotions.

\footnotetext{
${ }^{11}$ There is also declining pattern of promotion rates from the third year of duration in previous rank for the other columns, but because of the smaller number of observations, the pattern is less strong.
} 


\subsection{A discrete-time hazard rate model for promotions}

Since the promotion process is truly discrete in our application, we consider a discrete-time semi-parametric hazard rate model of promotion. The model allows the hazard rate to depend in a fully flexible way on time in the current rank. More specifically, define the hazard rate $h_{j t}^{r}$ as the probability that professor $j$ who is currently in rank $r$ promotes to the next rank $r+1$ at time $T_{j}^{r}=t$, given that he has not yet been promoted. Specify the hazard rate as the logistic function

$$
\begin{aligned}
h_{j t}^{r} & =\operatorname{Pr}\left[T_{j}^{r}=t \mid T_{j}^{r} \geqslant t, x_{j t}\right] \\
& =\frac{1}{1+\exp \left(-\alpha^{r}(t)-v_{j t}^{r}\right)} .
\end{aligned}
$$

The logistic specification ensures that the hazard rate lies between 0 and 1 . If one would want to specify a proportional hazard rate, the log-log model would be more appropriate [Holford (1976) and Prentice and Gloeckler (1978)]. Nevertheless, the logistic model converges to a proportional hazard model as the time interval becomes small [Thompson (1977)].

The hazard rate depends on time and on other variables. First, the hazard rate depends on time through the function $\alpha^{r}(t)$. One may specify functions that are increasing or decreasing in time. ${ }^{12}$ Alternatively, one may specify the time dependence semi-parametrically by including a full set of time in rank effects $\alpha_{t}^{r}(t=1,2, \cdots)$. Given that institutional constraints may affect the probabilities of promotion differently in the first years, we follow the semi-parametric approach here.

Second, the hazard rate depends on other variables through $v_{j t}^{r}$. We consider three sets of variables: durations in previous ranks, teaching and research performance, and individual and contract characteristics. To illustrate, consider the following specification for professors in $\operatorname{rank} r=3$ :

$$
v_{j t}^{3}=\beta_{1}^{3} D U R_{j}^{1}+\beta_{2}^{3} D U R_{j}^{2}+\gamma^{3} P E R F_{j t}+\delta^{3} O T H E R_{j t} .
$$

$P E R F_{j t}$ is a vector of teaching and research performance variables. Teaching performance is teaching load. Research performance is the annual average number of publications and impact over the last 5 years. ${ }^{13}$ Since Table 3 documented that performance differs substantially

\footnotetext{
${ }^{12}$ For example, in the proportional $\log$-log hazard rate model, one could specify $\alpha^{r}(t)=\alpha_{0}+\alpha_{1} \log t$, to have the well-known Weibull model.

${ }^{13}$ The university evaluates research based on the last five years. Since we only observe publications since 1991, we cannot take the average of the last five years for the first years in our data set. We therefore took the average over the longest available period up to a maximum of five years. Our results are robust when we use alternative measures, e.g. publications during the current academic year.
} 
across the three groups (humanities, exact and medical sciences), we interact both teaching and research performance by group dummy variables.

$O T H E R_{j t}$ refers to individual characteristics such as sex, nationality and Ph.D. origin, and contract characteristics such as tenure and full-time status. It also includes rank cohort effects, which refer to the academic year at which previous promotion took place. The rank cohort effects capture the possibility that the number of promotion slots was lower during certain years because of government restrictions or budget cuts.

Finally, $D U R_{j}^{1}$ and $D U R_{j}^{2}$ are state variables entering the hazard rate: $D U R_{j}^{1}$ is the duration in rank 1 , and $D U R_{j}^{2}$ is the duration in rank $2 .{ }^{14}$ The signs and magnitudes of $\beta_{1}^{3}$ and $\beta_{2}^{3}$ enable us to assess the relevance of the learning models of Harris and Holstrom (1982) and Chiappori et al. (1999). First, as discussed in section 2, the model of symmetric learning about workers' ability predicts the presence of fast tracks, i.e. professors who were quickly promoted to previous ranks have a higher probability of being promoted to the next rank. This means that $\beta_{1}^{3}<0$ and $\beta_{2}^{3}<0$ : promotion is more likely the shorter the duration in rank 1 or rank 2, holding constant the duration in other ranks. Second, the learning model predicts the late beginner property: holding constant total duration in rank 1 and 2 $\left(D U R_{j}^{1}+D U R_{j}^{2}\right)$ the promotion is more likely for a professor with a high duration in rank $1\left(D U R_{j}^{1}\right)$, i.e. a late beginner. To see what this implies for the parameters, it is convenient to rewrite the specification (2) as

$$
v_{j t}^{3}=\left(\beta_{1}^{3}-\beta_{2}^{3}\right) D U R_{j}^{1}+\beta_{2}^{3}\left(D U R_{j}^{1}+D U R_{j}^{2}\right)+\gamma^{3} P E R F_{j t}+\delta^{3} O T H E R_{j t} .
$$

According to the late beginner property, $D U R_{j}^{1}$ has a positive impact on the promotion probability to rank 3 , holding constant $D U R_{j}^{1}+D U R_{j}^{2}$, so that $\beta_{1}^{3}-\beta_{2}^{3}>0$. Combining the fast track and late beginner properties, we therefore have the testable prediction $\beta_{2}^{3}<\beta_{1}^{3}<0$. Intuitively, the duration in the most recent rank 2 has the strongest negative effect on the probability of promotion. The duration in the earlier rank 1 has a weaker but still negative effect. $^{15}$

More generally, we specify the variable $v_{j t}^{r}$ for a professor $j$ currently in rank $r$ at time $t$ as follows:

$v_{j t}^{r}=\beta_{-1}^{r} A G E_{j}+\beta_{0}^{r} D U R_{j}^{0}+\beta_{1}^{r} D U R_{j}^{1}+\cdots+\beta_{r-2}^{r} D U R_{j}^{r-2}+\beta_{r-1}^{r} D U R_{j}^{r-1}+\gamma^{r} P E R F_{j t}+\delta^{r} O T H E R_{j t}$,

\footnotetext{
${ }^{14}$ The duration in previous states has been included in other applications. For example, Heckman et al. (1985) include the time between two births in the hazard rate for an additional birth.

${ }^{15}$ Our empirical approach to test the late-beginner property differs from Chiappori et al. (1999). We test it directly using duration in previous ranks, whereas they first classify individuals into categories of early starters and late beginners prior to estimation.
} 
where $D U R_{j}^{0}$ refers to the duration at the university prior to entering professorship (i.e. as a Ph.D. or postdoc) and $A G E_{j}$ refers to age at earliest entry in the university. The learning model predicts that $\beta_{r-1}^{r}<\beta_{r-2}^{r}<\cdots<\beta_{-1}^{r}<0$ : professors with long durations in previous ranks have a lower probability of being promoted and the negative effects are strongest for the most recent durations.

Remark that our earlier analysis in section 4 showed that a large fraction of professors were internal entrants already employed at the university before entering rank 1 . For these professors all duration variables are positive. But there are also external entrants at rank 1, for whom $D U R_{j}^{0}=0$, or professors entering at ranks 2 or 3 , for whom $D U R_{j}^{1}=0$ and/or $D U R_{j}^{2}=0$. These zero durations may have different effects from positive but small durations. To account for this, we include three dummy variables for the types of entrants: external, rank 2 and rank 3 entrants.

We estimate the model using maximum likelihood. We take into account that our data are censored because the data set ends in 2007: for individuals that have not yet achieved the highest rank we therefore do not observe their complete duration in ranks history. This is a situation of independent censoring, since all individuals stopped being observed in 2007 , regardless of their promotion probability. As first noted by Brown (1975) and further developed by Allison (1982), it is possible to simplify the likelihood function so that it can be estimated as a binary dependent variable model after suitably organizing the data set. ${ }^{16}$ With this data set and the hazard specification (1), the model can be estimated as a simple binary logit model.

\subsection{Empirical results}

We first estimated the logistic hazard rate model (1) with only the time in current rank effects $\left(\alpha_{t}^{r}\right)$ and no other covariates. This model exactly replicates the inverse U-shaped pattern of the promotion rates as reported earlier in the "All" row of Table 7, with the very low promotion rates during the first two years because of the administrative restrictions. ${ }^{17}$ This model furthermore establishes that the inverse U-shaped pattern is highly significant, rejecting specification with a constant or a monotone increasing or decreasing hazard rate.

We next extended the model to include duration in previous rank effects $(D U R)$ and individual and contract characteristics $(O T H E R)$, but not yet the performance measures (Table 8). Finally, in Table 9, we estimated the complete model, which also includes the

\footnotetext{
${ }^{16}$ First, organize the data set such that every observation is an individual-year. Then, for each rank, define a binary dependent variable equal to zero if promotion did not occur and equal to 1 when promotion occurs.

${ }^{17}$ The logistic model can also replicate the other promotion rates in Table 7 by interacting the time in rank effects $\alpha_{t}^{r}$ with time in previous rank effects.
} 
teaching and research performance measures $(P E R F)^{18}$.

Table 8, as mentioned above, presents the empirical results of the hazard rate model (1) with duration in previous rank effects, and individual and contract characteristics, but not yet the performance measures. Several of the individual and contract characteristics play a significant role. Women in rank 1 and 3 tend to have a significantly lower probability of promoting to the next level. The same holds for foreigners in rank 2. The origin of the Ph.D. degree plays a mixed role. For example, a Ph.D. degree from a foreign university has a positive impact on the probability of promotion to rank 2 , but not on the promotion probabilities to higher ranks (suggesting that general human capital acquired abroad may only play a short-term role). Part-time professors have a significantly lower promotion probability in all three ranks, whereas tenured professors have a significantly higher promotion probability in all three ranks. External entrants (i.e. professors who were not employed at the university before entering professorship) have a significantly higher promotion probability when they are in rank 2, but not when they are in other ranks. Professors who skipped rank 1 as the port of entry and immediately entered in rank 2 or 3 have a significantly lower probability of being promoted than professors who entered in rank 1 . These findings suggest a mixed role for both general and firm-specific human capital in the promotion process.

Most interesting for assessing the relevance of the learning model are the duration in previous rank effects. First, all the duration effects are negative and highly significant. This suggests the presence of fast tracks, i.e. short durations in previous ranks imply higher subsequent promotion probabilities. Second, the negative duration effects are larger (in absolute value) for the more recent ranks. The hypothesis that the duration in previous rank effects are equal can be rejected at the $1 \%$ significance level for rank 3 professors promoted to rank 4 and at the $9 \%$ significance level for rank 2 professors promoted to rank 3 (2-sided Wald tests). For example, the promotion probability of a rank 3 professor to rank 4 is especially high if his duration in rank 2 was short. Short durations in the more distant rank 1 or rank 0 (Ph.D. or postdoc) increase the promotion probability to a lesser extent, and a young age at first entry has the lowest impact on the promotion probability. The promotion probabilities to rank 2 and 3 show similar declining duration effects. As discussed above, these declining duration in previous rank effects indicate the presence of the late beginner property, as also predicted by the learning model.

However, both the evidence for fast tracks and the late beginner property may stem

\footnotetext{
${ }^{18}$ As mentioned earlier, we estimate the hazard model after excluding all professors whose career was impacted by the ranking reform. As an alternative approach, we also estimated the model with the full data set for the period 1991-2006, after adding a dummy variable for duration in rank $1\left(D U R_{j}^{1}\right)$ interacted with a dummy variable for professors impacted by the reform. Both approaches gave qualitatively very similar results.
} 
from the fact that we have not yet included performance measures as explanatory variables. Accounting for performance may especially matter for these results since performance tends to be highly persistent over time. It is therefore important to assess whether the findings on the learning model remain in the complete model.

The complete model does not only include the time in current rank effects $\left(\alpha_{t}^{r}\right)$, the duration in previous rank effects $(D U R)$ and the individual and contract characteristics $(O T H E R)$, but in addition also the teaching and research performance measures (PERF). Interestingly, the complete model still yields the inverse U-shaped pattern for the time in current rank effects $\left(\alpha_{t}^{r}\right)$. Figure 5 converts the estimated $\alpha_{t}^{r}$ into hazard rates for a representative individual with average characteristics. This shows the promotion hazard rate is extremely small during the first two years when the administrative restrictions prevent promotions. The promotion hazard rate increases sharply in the third year and subsequently shows a gradual decrease while remaining significantly larger than in the first two years. This pattern suggests that the administrative restrictions on promotions in the first two years are effectively binding. In the third and fourth year there appears to be a catching up with higher promotion rates, which then gradually return to more "normal" lower levels. It is interesting to see that a similar pattern is found for promotions hazard rates in all ranks.

We can summarize this discussion as follows:

Observation 8 Because of administrative restrictions the promotion rates are significantly lower during the first two years. They increase sharply in the third and fourth year and then gradually decline, indicating the administrative restrictions form a binding constraint.

Table 9 shows the parameter estimates of the other variables. The findings for the individual and contract characteristics remain qualitatively similar, but the magnitudes may differ. For example, while a part-time position still has a negative impact on the promotion probability, the effect is considerably smaller and is at best only marginally significant. This shows that being full-time is not rewarded per se, but rather because it results in stronger teaching and/or research performance.

More importantly, including the performance variables has an impact on the estimated duration in previous rank effects. The estimated effects are still negative and highly significant, and their magnitudes are still declining from the most recent to older ranks. However, two observations are noteworthy. First, the estimated rank effects become smaller (in absolute value). Hence, part of the estimated fast track effect is eliminated after including the performance characteristics, as may be expected if performance shows some persistence over time. Second, the declining pattern from most recent to older ranks becomes weaker. The hypothesis that the duration in previous rank effects are equal can now only be rejected at 
the $7 \%$ significance level for rank 3 professors promoted to rank 4 , and it can only be rejected at the $23 \%$ significance level for rank 2 professors promoted to rank 3 (2-sided Wald tests). The evidence of a late beginner property therefore becomes considerably weaker than in the model without performance measures.

We can summarize these findings as follows.

Observation 9 The fast track and late beginner properties of the learning model have strong empirical support in the model without performance measures. In the model with research and teaching performance, the estimated magnitude of fast track effects is smaller but still significant, and the evidence for the late beginner property becomes weaker.

How should we relate this conclusion to earlier findings in the literature? On the one hand, it suggests that previous work such as Chiappori et al. (1999) has overestimated the relevance of learning theories because it has not properly controlled for performance measures. But on the other hand, we do find at least some weak evidence in favor of the learning model. Also, the importance of learning may be less relevant in universities than in private companies because universities may have better information about new hires' ability and because the job content changes less as one moves up in the hierarchy. Future research with performance data (based on other universities and/or private companies) may yield further insight in the role of the learning model when performance is accounted for.

We can now turn to the estimated effects of the performance measures. The number of administrative duties do not appear to play a significant role, except for promotion to the highest rank. However, this performance variable is only an imperfect variable and does not capture many of the administrative tasks. Teaching performance refers to the actual teaching load, i.e. number of week-hours (with 1 week-hour corresponding to 26-30 hours of teaching per year). Research performance is the annual average of the 5-year cumulative number of publications and average impact in three areas: SSCI, SCIE and Proceedings. We have interacted both the teaching and the research measures by the three university groups (humanities, exact and medical sciences), since Table 3 documented large differences in cultures and standards across the three groups.

Table 9 shows that teaching load has a positive and highly significant impact on the promotion probabilities for professors in almost all ranks and groups. The only insignificant effect of teaching load is for promotion to rank 4 in humanities. The positive effects are quantitatively the highest in medical sciences, but this is because the average teaching load in medical sciences in lower than elsewhere, as shown earlier in Table 3. Teaching load has an equal effect on the promotion probability to rank 2 and rank 3 . It has a smaller effect 
on the promotion probability to rank 4, at least for professors in humanities and medical sciences.

Professors in humanities have significantly higher promotion probabilities to any rank if they have published a lot in their own field, SSCI. Professors in humanities also have higher promotion probabilities to rank 2 and 3 if they have published more in SCIE, and they have higher promotion probabilities to rank 4 if they have published in Proceedings. Publication impact does not appear to positively influence promotion probabilities for professors in humanities.

Professors in exact and medical sciences do not show increased promotion probabilities if they have published in SSCI, which is outside their field. But they do show significantly higher promotion probabilities if they have published in SCIE and Proceedings. Furthermore, publication impact has positive and significant effects on their probability of being promoted, in contrast with the lack of such an effect for professors in humanities. This may be due to a stronger recognition of publication impact in exact and medical sciences, or because impact is better measured here than in humanities. Professors in medical sciences are not rewarded for publications in SCIE when considered for promotion to rank 4, but they are still rewarded for publications in Proceedings. For professors in exact sciences, the opposite is true: they are not rewarded for publications in Proceedings, but they still are for publications in SCIE.

It is interesting to note that we estimate a much higher effect of the number of publications on the promotion probability for professors in humanities than for professors in medical or exact sciences. For example, the effect of a SSCI publication on the promotion probability of a humanities professor varies between 0.83 and 1.11, whereas the effect of a SCIE publication on the promotion probability of an exact sciences professor is only between 0.06 and 0.20. This large difference is largely due to the fact that the average number of publications of exact sciences professors in SCIE is about 10 times larger than that of humanities professors in SSCI (as shown earlier in Table 3). Hence, performance evaluation tends to be relative to the other individuals in the same group. One interpretation could be that articles have more coauthors in medical and exact sciences than in humanities, such that one additional publication receives less in medical and exact sciences than in humanities.

It is also of interest to compare the magnitudes at which teaching and research are rewarded (bearing in mind the differences in publications across groups shown in Table 3). To illustrate, consider the promotion probabilities to rank 2. In humanities, an annual groupaverage of 0.3 publications per year in SSCI seems equivalent to a teaching load of about 2.4 week-hours (or about half of the average teaching load in humanities of 5.3 hours). ${ }^{19}$ In exact sciences an average of 3 publications per year in SCIE seems equivalent with a teaching

\footnotetext{
${ }^{19}$ We find the equivalence in teaching load using the following calculation: $\frac{0.3(1.11)}{0.14}=2.4$.
} 
load of 1.6 week-hours (less than $1 / 3$ of the average teaching load of 5.4 hours). In medical sciences, an average of 4.5 publications per year gives the same promotion probability as a teaching load of 3.4 week-hours (which is the average teaching load in medical sciences). These calculations are only illustrative, but they indicate that there are differences in the relative weight attached to teaching and research across the three disciplines.

We finally extended the model to allow the performance variables to have different effects on promotion probabilities in the second half of the sample period (after 2001). These results (not shown) indicate that the university did not change its policy over the period, for example by rewarding research more relative to teaching in recent years.

We summarize the role of performance measures as follows:

Observation 10 Both teaching and research performance play an important role in explaining promotion probabilities. There are important differences between the three main groups.

\subsection{Sensitivity analysis}

The previous section estimated a discrete-time hazard rate model of promotion. This model assumes promotion depends on absolute performance, since a professor's promotion probability depends on its own characteristics and not on the characteristics of other professors that are being consider for promotion at the same time. However, it appears plausible to expect that promotions are based on relative performance evaluation because of the institutional rules of the university discussed earlier. Each year the university allocates a fixed number of promotion slots for each group. Professors then participate in a promotion "tournament" and the highest ranked candidates per group promote to the next level. We had attempted to account for the possibility of relative performance evaluation by including a full set of cohort fixed effects, denoting the academic year at which a professor was promoted to this current rank.

In this section we will more directly take into account the institutional rules of the university and estimate a model of relative performance evaluation. We propose a discrete choice model that explicitly models the decision process within the university. Traditional discrete choice models, such as multinomial logit, assume that the decision maker may choose 1 out of a fixed set of $J$ alternatives. From the observed choice, one can infer that this choice

gives the highest utility across all available alternatives. In the current situation, the decision maker (the university) chooses the $K$ most preferred alternatives (promotion slots) out of a 
fixed set of $J$ alternatives (eligible professors), where $1 \leq K<J .^{20}$ It can be shown that the multinomial logit model easily generalizes to the case where a fixed number of $K$ alternatives are chosen.

More precisely, in each year $t$, for each rank $j$ and each university group $g$ (humanities, exact and medical sciences) we consider the promotion decision of each professor $j=1, \cdots, J_{t}^{r g}$. The university has $K_{t}^{r g}$ available promotion slots to the next rank $r+1$, with $1 \leq K_{t}^{r g}<J_{t}^{r g}$, and it uses an annual tournament for each rank and group to select the most preferred professors for promotion. To simplify notation we drop the superscripts $r$ and $g$ in the subsequent discussion (or equivalently, we subsume them in the subscript $t$ ). Let $y_{j t}$ be the promotion decision for professor $j$ at period $t$, taking values 1 for promotion and 0 otherwise. Let $\mathbf{y}_{t}=\left(y_{1 t}, \cdots, y_{J_{t} t}\right)$ be the overall tournament outcome at period $t$ (and rank/group). It is clear that $\sum_{j=1}^{J_{t}} y_{j t}=K_{t}$, i.e. the observed number of ones is equal to the number of available promotion slots. As shown by for example Hamerle and Ronning (1995), the probability of observing the overall tournament outcome $\mathbf{y}_{t}$, conditional on observing $K_{t}$ promotions, is equal to

$$
\operatorname{Pr}\left(\mathbf{y}_{t} \mid \sum_{j=1}^{J_{i}} y_{j t}=K_{t}\right)=\frac{\exp \left(\sum_{j=1}^{J_{i}} y_{j t}\left(-\alpha(t)-v_{j t}\right)\right)}{\sum_{\mathbf{d}_{t} \in S_{t}} \exp \left(\sum_{j=1}^{J_{t}} d_{j t}\left(-\alpha(t)-v_{j t}\right)\right)},
$$

Here, $\mathbf{d}_{t}=\left(d_{1 t}, \cdots, d_{J_{t} t}\right)$, where $d_{i j}$ equals 0 or $1, \sum_{j}^{J_{i}} d_{i j}=K_{i}$, and $S_{t}$ is the set of all possible combinations with $K_{t}$ chosen alternatives and $J_{t}-K_{t}$ non-chosen alternatives. Note that this model is also equivalent to a discrete-time version of the Box-Cox model accounting for ties.

We estimate this tournament model of relative performance for promotions to rank 2, rank 3 and rank 4. For each rank we observe a total of 48 tournaments, i.e. the 16 years during 1991-2006 multiplied by the three university groups. But the informational content of each tournament is higher than in a traditional multinomial logit model, since we do not observe a single selected alternative but rather $K_{t}$ selected alternatives per tournament.

Table 10 shows the empirical results for the complete model, i.e. including time in current rank effects, duration in previous rank effects and contract and individual characteristics. Cohort fixed effects are no longer included since the model is already one of relative performance. The parameter estimates are remarkably close to those obtained from the earlier discrete-time hazard model of promotion with cohort fixed effects (Table 9). The statistical significance of the parameter estimates also remains very similar. This is true for both the individual and contract characteristics and the performance variables. If anything, it ap-

\footnotetext{
${ }^{20}$ If one would observe $K=0$ or $K=J$, the observation on the decision maker would not contain useful information.
} 
pears that the learning theory of promotions has even somewhat weaker empirical support. The duration in past rank effects remain negative and highly significant (fast tracks), but less so than in the discrete-time hazard rate model of Table 9. Furthermore, the duration in past rank effects still have a declining pattern from most recent to older ranks (late beginner property), but the hypothesis that they are equal cannot be rejected at the $11 \%$ significance level for rank 3 professors promoted to rank 4 (versus $7 \%$ significance level in the hazard rate model), and it cannot be rejected at the $48 \%$ significance level for rank 2 professors promoted to rank 4 (versus $23 \%$ significance level before).

In sum, the empirical results from the tournament model of promotions yield the same conclusions as our earlier results from the hazard rate model of promotions.

\section{Conclusion}

We collected a rich personnel data set of a large European university. A unique feature of our data is the relatively simple personnel policy rules compared to other studies. Furthermore, we have good measures of performance in contrast with previous studies. These features make the data set particularly well-suited to study the relevance of internal labor market theories.

We find strong evidence for Doeringer and Piore's two conditions for the existence of an internal labor market, considerably stronger than evidence found in other work. First, the lowest academic rank is a strong port of entry and the highest rank is a port of exit. In fact, in the large majority of cases entry occurs even prior to entering the academic ranks (at the Ph.D. or post-doctoral stage). To the extent that exit occurs before the highest academic rank it is because retirement age has already been reached, which has not been documented in earlier studies. Second, wages do not follow external wage developments, since they follow administrative rules that have not been modified for a long time.

Having established the presence of an internal labor market, we subsequently look at internal promotion dynamics to assess the relevance of alternative internal labor market theories. Consistent with incentive theories, research and teaching performance turn out to be crucial determinants of promotion dynamics. Learning theories of internal labor markets appear to have support when we do not account for observed performance, but the evidence becomes much weaker once we control for performance. These findings suggest the need for further research on other companies and/or universities, to see how earlier conclusions are affected once good measures of performance are taken into account.

Finally, we find that administrative rigidities play an important role in explaining promotion dynamics. For example, the university has a rule of not promoting individuals within 
the first two years of a previous promotion. It turns out that this rule is largely followed, and that it constitutes an effective constraint on promotion probabilities, since there is a disproportionate increase in the hazard rate of promotion in the third and fourth year. This example suggests that administrative rules constrain personnel policies and may entail inefficiencies. Further comparative research on other universities would be required to see whether this conclusion can be generalized to guide policy reforms. 
Aghion, Philippe, Mathias Dewatripont, Caroline Hoxby, Andreu Mas-Colell, and Andre Sapir, "Why Reform Europe's Universities?," Brugelpolicybrief, 9 2007, 4, $1-8$.

Allison, Paul D., "Discrete-Time Methods for the Analysis of Event Histories," Sociological methodology, 1982, 13, 61-98.

Baker, George, Michael Gibbs, and Bengt Holmstrom, "The Internal Economics of the Firm: Evidence from Personnel Data," The Quarterly Journal of Economics, November 1994, 109 (4), 881-919.

Becker, Gary S., "Investment in Human Capital: A Theoretical Analysis," Journal of Political Economy, 1962, 70, 9.

Brown, Charles C., "On the Use of Indicator Variables for Studying the Time-Dependence of Parameters in a Response-Time Model," Biometrics, 1975, 31 (4), 863-872.

Chiappori, Pierre-Andre, Bernard Salanie, and Julie Valentin, "Early Starters versus Late Beginners," Journal of Political Economy, August 1999, 107 (4), 731-760.

Coupé, Tom, Valérie Smeets, and Frédéric Warzynski, "Incentives, Sorting and Productivity along the Career: Evidence from a Sample of Top Economists," Journal of Law, Economics and Organization, April 2006, 22 (1), 137-167.

DeVaro, Jed and Michael Waldman, "The signaling role of promotions: Further theory and empirical evidence," MPRA Paper 1550, University Library of Munich, Germany Dec 2006.

Doeringer, Peter B. and Michael J. Piore, Internal Labor Markets and Manpower Analysis, M E Sharpe Inc, 1971.

Farber, Henry S. and Robert Gibbons, "Learning and Wage Dynamics," The Quarterly Journal of Economics, November 1996, 111 (4), 1007-47.

Gibbons, Robert and Michael Waldman, "A Theory Of Wage And Promotion Dynamics Inside Firms," The Quarterly Journal of Economics, November 1999, 114 (4), $1321-1358$.

Groysberg, Boris, Ashish Nanda, and Nitin Nohria, "The Risky Business of Hiring Stars," Harvard Business Review, 2004. 
Hallock, Kevin F., "Seniority and Monopsony in the Academic Labor Market: Comment," American Economic Review, June 1995, 85 (3), 654-57.

Hamerle, Alfred and Gerd Ronning, Panel analysis for qualitative variables, In Handbook of Statistical Modeling for the Social and Behavioral Sciences, New York: Plenum Press, 1995.

Harris, Milton and Bengt Holstrom, "A Theory of Wage Dynamics," Review of Economic Studies, July 1982, 49 (3), 315-33.

Heckman, James J., Joseph V. Hotz, and James R. Walker, "New Evidence on the Timing and Spacing of Births," American Economic Review, May 1985, 75 (2), 179-84.

Holford, Theodore R., "Life Tables with Concomitant Information," Biometrics, 1976, $32(3), 587-597$.

Holmstrom, Bengt, "Moral Hazard and Observability," The Bell Journal of Economics, 1979, 10 (1), 74-91.

Kahn, Lisa B. and Fabian Lange, "Employer Learning, Productivity and the Earnings Distribution: Evidence from Performance Measures," Technical Report, Yale University 2009.

Lazear, Edward P., "The Job as a Concept," Papers e-90-24, Stanford - Hoover Institution 1990.

- and Paul Oyer, "Internal and external labor markets: a personnel economics approach," Labour Economics, October 2004, 11 (5), 527-554.

_ and _, "Personnel Economics," NBER Working Papers 13480, National Bureau of Economic Research, Inc Oct 2007.

- and Sherwin Rosen, "Rank-Order Tournaments as Optimum Labor Contracts," Journal of Political Economy, October 1981, 89 (5), 841-64.

Nalebuff, Barry J. and Joseph E. Stiglitz, "Prices and Incentives: Towards a General Theory of Compensation and Competition," Bell Journal of Economics, Spring 1983, 14 (1), 21-43.

Oyer, Paul, "Ability and employer learning: Evidence from the economist labor market," Journal of the Japanese and International Economies, June 2008, 22 (2), 268-289. 
Prentice, R. L. and L. A. Gloeckler, "Regression Analysis of Grouped Survival Data with Application to Breast Cancer Data," Biometrics, 1978, 34 (1), 57-67.

Ransom, Michael R., "Seniority and Monopsony in the Academic Labor Market," American Economic Review, March 1993, 83 (1), 221-33.

Rosen, Sherwin, "Prizes and Incentives in Elimination Tournaments," American Economic Review, September 1986, 76 (4), 701-15.

Rosenblum, Gerald and Barbara Rubin Rosenblum, "Segmented Labor Markets in Institutions of Higher Learning," Sociology of Education, 1990, 63 (3), 151-164.

Thompson, W. A. Jr., "On the Treatment of Grouped Observations in Life Studies," Biometrics, 1977, 33 (3), 463-470.

Treble, John, Edwin van Gameren, Sarah Bridges, and Tim Barmby, "The internal economics of the firm: further evidence from personnel data," Labour Economics, December 2001, 8 (5), 531-552.

Waldman, Michael, "Theory and evidence in internal labor markets," MPRA Paper 5113, University Library of Munich, Germany Oct 2007. 


\section{Tables}

\section{Table 1: VARIABLES List}

\begin{tabular}{|c|c|}
\hline $\begin{array}{l}\text { Variable name } \\
\text { ID } \\
\text { Acyear }\end{array}$ & $\begin{array}{l}\text { Description } \\
\text { employee unique identifier number } \\
\text { academic year }\end{array}$ \\
\hline \multicolumn{2}{|c|}{ Individual and Contract Characteristics } \\
\hline Age & age in years (day precision) \\
\hline Female & gender indicator $=1$ for female,$=0$ for male \\
\hline Foreign & nationality indicator $=1$ for foreigners, $=0$ for locals \\
\hline Ph.D. own university & $=1$ if last $\mathrm{Ph} . \mathrm{D}$. is from this university \\
\hline Ph.D. same country & $=1$ if last Ph.D. is from the same country but a different university \\
\hline Ph.D. world & $=1$ if last $\mathrm{Ph} . \mathrm{D}$. is from a university outside of this country \\
\hline External entrant & indicator $=1$ if external entrant, $=0$ if not \\
\hline Rank 1 entrant & indicator $=1$ if enters professorship in rank $1,=0$ if not \\
\hline Rank 2 entrant & indicator $=1$ if enters professorship in rank $2,=0$ if not \\
\hline Rank 3 entrant & indicator $=1$ if enters professorship in rank $3,=0$ if not \\
\hline Rank 4 entrant & indicator $=1$ if enters professorship in rank $4,=0$ if not \\
\hline Rank number & $=0$ non professorship ranks, $=1,2,3$ and 4 for professorship \\
\hline Part-time university & $=1$ if working part-time at the university, $=0$ if full-time \\
\hline Tenure & $=1$ if tenured, $=0$ if temporary \\
\hline Seniority & wage seniority in rank \\
\hline Group & standardized group name \\
\hline \multicolumn{2}{|l|}{ Duration Variables } \\
\hline Age at entry & age at entry in any rank \\
\hline Duration - rank 0 & number of years prior to rank 1 \\
\hline Duration - rank 1 & number of years in rank 1 \\
\hline Duration - rank 2 & number of years in rank 2 \\
\hline Duration - rank 3 & number of years in rank 3 \\
\hline Duration - rank 4 & number of years in rank 4 \\
\hline \multicolumn{2}{|c|}{ Performance Measures } \\
\hline Highest duty & highest duty level ( 1 to 5 with $5=$ lowest) \\
\hline Number of duty & total number of duties in the academic year \\
\hline Teaching load & teaching load in week-hours \\
\hline SCIE publication & total number of publications in SCIE \\
\hline SCIE impact factor & average impact factor in SCIE \\
\hline SSCI publication & total number of publications in SSCI \\
\hline SSCI impact factor & average impact factor in SSCI \\
\hline Proceedings & total number of publications in Proceedings \\
\hline
\end{tabular}


Table 2: Summary Statistics

\begin{tabular}{|c|c|c|c|c|}
\hline \multirow{2}{*}{\multicolumn{5}{|c|}{ Number of }} \\
\hline & & & & \\
\hline Observations & 36,284 & & 22,197 & \\
\hline Professors & 2691 & & 2282 & \\
\hline \multirow{3}{*}{\multicolumn{5}{|c|}{$\begin{array}{l}\text { Variables } \\
\text { Individual and Contract } \\
\text { Characteristics }\end{array}$}} \\
\hline & & & & \\
\hline & & & & \\
\hline Age & 36,284 & 48.73 & 22,197 & 48.89 \\
\hline Female & 36,284 & 0.09 & 22,197 & 0.13 \\
\hline Foreign & 36,284 & 0.04 & 22,197 & 0.04 \\
\hline Ph.D. own university & 22,950 & 0.86 & 17,070 & 0.85 \\
\hline Ph.D. same country & 22,950 & 0.06 & 17,070 & 0.06 \\
\hline Ph.D. world & 22,950 & 0.08 & 17,070 & 0.09 \\
\hline External entrant & 36,284 & 0.18 & 22,197 & 0.15 \\
\hline Rank 1 entrant & 36,284 & 0.87 & 22,197 & 0.86 \\
\hline Rank 2 entrant & 36,284 & 0.06 & 22,197 & 0.10 \\
\hline Rank 3 entrant & 36,284 & 0.04 & 22,197 & 0.02 \\
\hline Rank 4 entrant & 36,284 & 0.03 & 22,197 & 0.01 \\
\hline Rank 1 & 36,284 & 0.27 & 22,197 & 0.22 \\
\hline Rank 2 & 36,284 & 0.16 & 22,197 & 0.26 \\
\hline Rank 3 & 36,284 & 0.15 & 22,197 & 0.19 \\
\hline Rank 4 & 36,284 & 0.41 & 22,197 & 0.33 \\
\hline Part-time university & 35,175 & 0.30 & 21,502 & 0.33 \\
\hline Tenure & 36,277 & 0.84 & 22,197 & 0.85 \\
\hline Seniority & 28,148 & 9.89 & 18,877 & 11.73 \\
\hline Medical Sciences Grp. & 35,547 & 0.31 & 22,173 & 0.35 \\
\hline Exact Sciences Grp. & 35,547 & 0.29 & 22,173 & 0.30 \\
\hline Humanities Grp. & 35,547 & 0.38 & 22,173 & 0.34 \\
\hline Other Grp. & 35,547 & 0.01 & 22,173 & 0.01 \\
\hline \multicolumn{5}{|l|}{ Duration Variables } \\
\hline Age at entry & 36,284 & 30.65 & 22,197 & 29.21 \\
\hline Duration - rank 0 & 36,284 & 6.39 & 22,197 & 7.45 \\
\hline Duration - rank 1 & 36,284 & 4.07 & 22,197 & 4.12 \\
\hline Duration - rank 2 & 36,284 & 1.22 & 22,197 & 2.00 \\
\hline Duration - rank 3 & 36,284 & 1.67 & 22,197 & 1.83 \\
\hline Duration - rank 4 & 36,284 & 4.68 & 22,197 & 3.86 \\
\hline \multicolumn{5}{|l|}{ Performance Measures } \\
\hline Highest Duty & 31,158 & 1.11 & 22,197 & 1.07 \\
\hline Number of Duty & 31,158 & 0.31 & 22,197 & 0.31 \\
\hline Teaching Load & 31,158 & 5.08 & 22,197 & 4.61 \\
\hline SCIE Publication & 20,741 & 2.52 & 20,741 & 2.52 \\
\hline SCIE Impact Factor & 20,741 & 2.02 & 20,741 & 2.02 \\
\hline SSCI Publication & 13,669 & 0.12 & 13,669 & 0.12 \\
\hline SSCI Impact Factor & 13,669 & 0.11 & 13,669 & 0.11 \\
\hline Proceedings & 14,947 & 0.27 & 14,947 & 0.27 \\
\hline
\end{tabular}

Note: Shows the number of observations and mean value of each variable of interest for the entire data set, 1972-2007, and for the subperiod 1991-2007. The information is complete or almost complete for most of the variables, except for performance measures prior to 1991. 


\section{Table 3: Performance by Group Summary Statistics}

\begin{tabular}{lcccccc} 
& \multicolumn{2}{c}{ Exact Sciences } & \multicolumn{2}{c}{ Humanities } & \multicolumn{2}{c}{ Medical Sciences } \\
Variables & Mean & St. Dev. & Mean & St. Dev. & Mean & St. Dev. \\
Teaching Load & 5.37 & 4.65 & 5.27 & 3.34 & 3.42 & 3.64 \\
SCIE Publication & 3.09 & 4.43 & 0.12 & 0.49 & 4.50 & 6.40 \\
SCIE Impact Factor & 1.86 & 2.19 & 0.16 & 0.67 & 4.08 & 3.58 \\
SSCI Publication & 0.02 & 0.13 & 0.30 & 0.65 & 0.04 & 0.20 \\
SSCI Impact Factor & 0.02 & 0.14 & 0.24 & 0.61 & 0.05 & 0.27 \\
Proceedings & 0.73 & 1.56 & 0.05 & 0.18 & 0.11 & 0.31
\end{tabular}

Note: Shows teaching and research performance for the subperiod 1991-2007 by group. Teaching is in week-hours over the academic year. Research performance measures are annual averages over the last 5 years, in line with the university promotion policy (which considers the last 5 years also).

\section{Table 4: Professorship Transition Matrix}

Academic Year 1991 to 2006 incl.

\begin{tabular}{|c|c|c|c|c|c|c|c|c|c|c|}
\hline & Rank 1 & Rank 2 & Rank 3 & Rank 4 & $\begin{array}{c}\text { Temp } \\
\text { Out }\end{array}$ & $\begin{array}{l}\text { Total } \\
\text { Exit }\end{array}$ & $\begin{array}{c}\text { Early } \\
\text { Exit }\end{array}$ & $\begin{array}{l}\text { Early } \\
\text { Retire }\end{array}$ & Retire & Total \\
\hline Int. Entry & 612 & 130 & 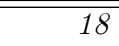 & $\overline{77}$ & - & 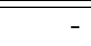 & - & - & - & 767 \\
\hline Delayed Int. Entry & 181 & 38 & 13 & 6 & - & - & - & - & - & 238 \\
\hline Ext. Entry & 155 & 54 & 32 & 19 & - & - & - & - & - & 260 \\
\hline Total Entry & 948 & 222 & 63 & 32 & - & - & - & - & - & 1,265 \\
\hline Rank 1 & 3,818 & 616 & 7 & 0 & 7 & 151 & 103 & 24 & 24 & 4,599 \\
\hline Rank 2 & 0 & 4,586 & 667 & 12 & 10 & 165 & 57 & 39 & 69 & 5,440 \\
\hline Rank 3 & 0 & 0 & 3,337 & 426 & 1 & 125 & 20 & 35 & 70 & 3,889 \\
\hline Rank 4 & 1 & 0 & 0 & 6,425 & 1 & 386 & 29 & 73 & 284 & 6,813 \\
\hline Temp Out & 7 & 9 & 4 & 3 & 48 & - & - & - & - & 71 \\
\hline Total & 4,774 & 5,433 & 4,078 & 6,898 & 67 & 827 & 209 & 171 & 447 & 22,077 \\
\hline
\end{tabular}

Note: The intersection of rows 5-8 and columns 1-4 shows the career transitions of professors employed in one of the four academic ranks. Non-promotions or stays are on the "diagonal" (starting from the fifth row onwards), promotions are to the right of this diagonal and demotions are to the left. Total Entry is the sum of internal, delayed internal and external entry (all rows displayed in italic). Total Exit is the sum of early exit, early retire and retire (all columns displayed in italic). Temp Out refers to professors who temporarily exit the university to return later in one of the four professorship ranks. A zero value truly means that this type of transition never took place, while "-" implies that this type of transition is not possible. 


\section{Table 5: BASIC CAREER CHARACTERISTICS STATISTICS}

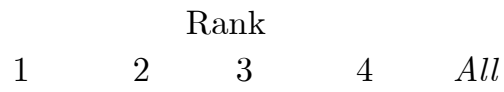

Total number of entrants and promoted into rank

\begin{tabular}{rrrrr}
915 & 1,140 & 706 & 443 & 3,204 \\
100.0 & 21.5 & 7.8 & 6.8 & 38.9 \\
84.5 & 17.0 & 3.7 & 2.7 & 31.4 \\
15.5 & 4.5 & 4.1 & 4.1 & 7.5 \\
0.0 & 78.5 & 92.2 & 93.2 & 61.1 \\
& & & & \\
151 & 165 & 125 & 386 & 827 \\
& & & & \\
68.2 & 34.5 & 16.0 & 7.5 & 25.3 \\
31.8 & 65.5 & 84.0 & 92.5 & 74.7 \\
& & & & \\
15.0 & 13.0 & 11.6 & na & 13.3 \\
3.1 & 3.0 & 3.2 & 5.7 & 3.1 \\
& & & & \\
\hline
\end{tabular}

Data set: Entrants into professorship between 1991 and 1999 incl.

Total number of all entrants into rank

$\begin{array}{rrrrr}549 & 110 & 26 & 13 & 698 \\ 3.6 & 2.7 & 11.5 & 15.4 & 4.0 \\ & & & & \\ 12.0 & 15.5 & 30.8 & 15.4 & 13.3 \\ 89.4 & 76.5 & 87.5 & 100.0 & 87.1 \\ 6.1 & 17.6 & 12.5 & - & 8.6 \\ 4.5 & 5.9 & - & - & 4.3 \\ & & & & \\ 84.3 & 81.8 & 57.7 & 69.2 & 82.7 \\ 18.1 & 23.3 & 26.7 & 100.0 & 20.5 \\ 27.6 & 26.7 & 73.3 & - & 28.2 \\ 25.5 & 50.0 & - & - & 28.2 \\ & & & & \\ 8.4 & 7.2 & 4.2 & 1.9 & 7.9 \\ 7.4 & 7.5 & 8.8 & 3.0 & 7.5\end{array}$

Avg. years in univ. prior to entry in professorship

Note: The top panel shows the entry, exit and career characteristics of professor-years from 1991 to 2006. To follow careers, while avoiding censoring problems, the bottom panel is restricted to all observations of professors hired between 1991 to 1999. 


\section{Table 6: Seniority Step Compliance}

\begin{tabular}{lccccc} 
& \multicolumn{5}{c}{ Rank number } \\
& Rank1 & Rank2 & Rank 3 & Rank4 & Total \\
Variation Within Rank & & & & & \\
$\quad$ levels too low & $0.2 \%$ & $0.1 \%$ & $0.0 \%$ & $0.0 \%$ & $0.1 \%$ \\
$\quad$ level too low & $0.5 \%$ & $1.5 \%$ & $0.7 \%$ & $0.4 \%$ & $0.7 \%$ \\
$\quad$ Right level & $97.1 \%$ & $90.7 \%$ & $88.2 \%$ & $96.1 \%$ & $93.3 \%$ \\
$\quad$ level too high & $0.2 \%$ & $3.4 \%$ & $5.6 \%$ & $1.9 \%$ & $2.9 \%$ \\
2 levels too high & $1.1 \%$ & $3.8 \%$ & $5.6 \%$ & $1.6 \%$ & $2.9 \%$ \\
\hline Total & $99.1 \%$ & $99.5 \%$ & $99.9 \%$ & $100.0 \%$ & $99.8 \%$ \\
& & & & & \\
Variation Upon Promotion & & & & & \\
2 levels too low & - & $15.1 \%$ & $21.3 \%$ & $18.8 \%$ & $19.2 \%$ \\
1 level too low & - & $24.5 \%$ & $28.5 \%$ & $18.4 \%$ & $23.9 \%$ \\
$\quad$ Right level & - & $50.0 \%$ & $43.0 \%$ & $58.9 \%$ & $50.4 \%$ \\
1 level too high & - & $5.7 \%$ & $2.1 \%$ & $0.5 \%$ & $2.2 \%$ \\
2 levels too high & - & $0.9 \%$ & $3.4 \%$ & $1.9 \%$ & $2.4 \%$ \\
\hline Total & - & $96.2 \%$ & $98.3 \%$ & 98.6 & $98.0 \%$
\end{tabular}

Note: The top panel shows the variation between the actual wage seniority and the predicted wage seniority when a professor remains in the same rank. The bottom panel shows the variation between the actual and the predicted wage seniority when a professor is promoted. The calculation uses data on full-time professors only, since the seniority steps of part-timers and full-timers are different and that of part-timers depend on the percentage of appointment. Also, data are restricted to 1999 to 2006 inclusively, because seniority steps could only be obtained for that period. 


\section{Table 7: Promotion Hazard Rates}

\begin{tabular}{c|rrrrrrrrr} 
Total duration & \multicolumn{1}{|c}{ Period present in rank 2 before promotion } \\
rank 1 & 1 & 2 & 3 & 4 & 5 & 6 & 7 & 8 & $9+$ \\
\hline 0 & - & 2 & 13 & 25 & 16 & 18 & 10 & 6 & 11 \\
1 & - & 17 & 14 & 18 & - & 14 & - & 40 & 8 \\
2 & - & 11 & 30 & 30 & 17 & 26 & 31 & 33 & 31 \\
3 & - & 4 & 41 & 39 & 28 & 21 & 12 & 8 & 12 \\
4 & 2 & 2 & 37 & 33 & 6 & 16 & 10 & 6 & 9 \\
5 & - & - & 18 & 16 & 24 & 20 & 43 & 17 & - \\
6 & 2 & 4 & 29 & 27 & 19 & 23 & - & - & 20 \\
7 & - & - & 24 & 36 & - & 43 & - & - & 100 \\
8 & - & - & 31 & 13 & - & - & - & - & - \\
$9+$ & - & 2 & 5 & 3 & 4 & 21 & 17 & 20 & 29 \\
\hline All & 0 & 3 & 25 & 26 & 15 & 20 & 15 & 11 & 12 \\
Nbr. Obs. & 829 & 762 & 659 & 448 & 299 & 215 & 151 & 109 & 296
\end{tabular}

\begin{tabular}{c|rrrrrrrrr} 
Total duration & \multicolumn{1}{|c}{ Period present in rank 3 before promotion } \\
rank 2 & 1 & 2 & 3 & 4 & 5 & 6 & 7 & 8 & $9+$ \\
\hline 0 & 2 & - & 14 & 16 & 13 & - & 21 & 11 & 11 \\
1 & - & - & - & - & - & - & - & 67 & 100 \\
2 & - & - & 24 & 44 & 11 & 29 & 25 & - & 40 \\
3 & 1 & - & 40 & 40 & 40 & 13 & 50 & 25 & - \\
4 & - & 3 & 42 & 34 & 36 & 33 & 14 & 17 & 10 \\
5 & - & 3 & 24 & 43 & 17 & 14 & - & - & - \\
6 & - & 3 & 27 & 10 & 7 & 30 & - & 20 & - \\
7 & - & - & 29 & - & - & - & 50 & - & - \\
8 & - & - & 27 & 25 & 20 & - & - & - & - \\
$9+$ & - & - & 8 & 4 & - & 40 & - & - & - \\
\hline All & 0 & 1 & 30 & 27 & 20 & 17 & 24 & 19 & 12 \\
Nbr. Obs. & 499 & 453 & 392 & 230 & 142 & 87 & 50 & 32 & 48
\end{tabular}

Note: Shows the promotion hazard rates controlling for current and prior rank duration of rank 2 professors (top panel) and rank 3 professors (bottom panel). 


\section{Table 8: Discrete-Time Promotion Hazard Model - Excluding Performance Measures}

\begin{tabular}{|c|c|c|c|c|c|c|c|c|c|}
\hline & \multicolumn{3}{|c|}{$\begin{array}{l}\text { Promotion to } \\
\text { Rank } 2\end{array}$} & \multicolumn{3}{|c|}{$\begin{array}{l}\text { Promotion to } \\
\text { Rank } 3\end{array}$} & \multicolumn{3}{|c|}{$\begin{array}{c}\text { Promotion to } \\
\text { Rank } 4\end{array}$} \\
\hline & Coef. & & Std.Err. & Coef. & & Std.Err. & Coef. & & Std.Err. \\
\hline \multirow{2}{*}{\multicolumn{10}{|c|}{$\begin{array}{l}\text { Individual and Contract } \\
\text { Characteristics }\end{array}$}} \\
\hline & & & & & & & & & \\
\hline female & -0.273 & $* *$ & $(0.119)$ & -0.011 & & $(0.159)$ & -0.684 & $* * *$ & $(0.246)$ \\
\hline foreign & 0.007 & & $(0.264)$ & -0.742 & $* *$ & $(0.329)$ & 0.288 & & $(0.484)$ \\
\hline Ph.D. same country & 0.299 & & $(0.220)$ & -0.750 & $* *$ & $(0.298)$ & -0.162 & & $(0.429)$ \\
\hline Ph.D. world & 0.570 & $* *$ & $(0.234)$ & -0.315 & & $(0.236)$ & 0.069 & & $(0.349)$ \\
\hline external entrant & 0.061 & & $(0.194)$ & 0.787 & $* * *$ & $(0.257)$ & -0.327 & & $(0.352)$ \\
\hline rank 2 entrant & & & & -0.719 & $* * *$ & $(0.197)$ & -0.506 & $*$ & $(0.290)$ \\
\hline rank 3 entrant & & & & & & & -2.157 & $* * *$ & $(0.449)$ \\
\hline part-time university & -0.659 & $* * *$ & $(0.133)$ & -0.560 & $* * *$ & $(0.163)$ & -1.101 & $* * *$ & $(0.245)$ \\
\hline tenure & 0.547 & $* * *$ & $(0.131)$ & 0.947 & $* * *$ & $(0.266)$ & 1.941 & $* *$ & $(0.781)$ \\
\hline group exact sc. & -0.246 & $*$ & $(0.128)$ & -0.257 & $*$ & $(0.155)$ & -0.230 & & $(0.226)$ \\
\hline group humanities & -0.249 & $* *$ & $(0.124)$ & -0.305 & $* *$ & $(0.151)$ & -0.226 & & $(0.226)$ \\
\hline group other & -1.131 & $* * *$ & $(0.390)$ & -0.746 & $*$ & $(0.428)$ & -0.126 & & $(0.872)$ \\
\hline \multicolumn{10}{|l|}{ Duration } \\
\hline age at entry & -0.054 & $* * *$ & $(0.011)$ & -0.078 & $* * *$ & $(0.015)$ & -0.083 & $* * *$ & $(0.024)$ \\
\hline duration rank 0 & -0.050 & $* * *$ & $(0.010)$ & -0.070 & $* * *$ & $(0.012)$ & -0.118 & $* * *$ & $(0.023)$ \\
\hline duration rank 1 & & & & -0.148 & $* * *$ & $(0.032)$ & -0.206 & $* * *$ & $(0.061)$ \\
\hline duration rank 2 & & & & & & & -0.280 & $* * *$ & $(0.055)$ \\
\hline Baseline Dummies & YES & & & YES & & & YES & & \\
\hline Rank Cohort Dummies & YES & & & YES & & & YES & & \\
\hline Observations Number & 4295 & & & 3364 & & & 1939 & & \\
\hline df & 36 & & & 36 & & & 39 & & \\
\hline 11 & -1480 & & & -1050 & & & -515.7 & & \\
\hline
\end{tabular}

Note: The empirical results are based on the logistic discrete time hazard rate model (1). In promotion to rank 2 , the data set used is all professor-years in rank 1 and the dependent variable is a promotion to rank 2 dummy. The same logic holds for promotion to ranks 3 and 4. All regressions include a full set of time in rank effects $\alpha_{t}^{r}(t=1,2, \cdots)$, referred to as baseline dummies. All regressions also include individual and contract characteristics, duration variables and rank cohort dummies. Data for the subperiod 1991-2006 are used and reform is accounted for. Standard errors are in parentheses. Coefficient significance is denoted using asterisks: $* * *$ is $\mathrm{p}<0.01,{ }^{*}$ is $\mathrm{p}<0.05$, and $*$ is $\mathrm{p}<0.1$ 


\section{Table 9: Discrete-Time Promotion Hazard Model - Including Performance Measures}

\begin{tabular}{|c|c|c|c|c|c|c|c|c|c|}
\hline & \multicolumn{3}{|c|}{$\begin{array}{c}\text { Promotion to } \\
\text { Rank } 2\end{array}$} & \multicolumn{3}{|c|}{$\begin{array}{c}\text { Promotion to } \\
\text { Rank } 3\end{array}$} & \multicolumn{3}{|c|}{$\begin{array}{c}\text { Promotion to } \\
\text { Rank } 4\end{array}$} \\
\hline & Coef. & & Std.Err. & Coef. & & Std.Err. & Coef. & & Std.Err. \\
\hline \multicolumn{10}{|l|}{ Individual and Contract } \\
\hline \multicolumn{10}{|l|}{ Characteristics } \\
\hline female & -0.232 & $*$ & $(0.126)$ & 0.078 & & $(0.171)$ & -0.428 & * & $(0.260)$ \\
\hline foreign & 0.017 & & $(0.276)$ & -0.670 & $*$ & $(0.352)$ & 0.218 & & $(0.530)$ \\
\hline Ph.D. same country & 0.092 & & $(0.238)$ & -0.927 & $* * *$ & $(0.326)$ & -1.009 & * & $(0.518)$ \\
\hline Ph.D. world & 0.485 & $*$ & $(0.255)$ & -0.330 & & $(0.256)$ & -0.062 & & $(0.407)$ \\
\hline external entrant & 0.067 & & $(0.202)$ & 0.817 & $* * *$ & $(0.270)$ & -0.269 & & $(0.384)$ \\
\hline rank 2 entrant & & & & -0.974 & $* * *$ & $(0.217)$ & -0.586 & $*$ & $(0.320)$ \\
\hline rank 3 entrant & & & & & & & -1.856 & $* * *$ & $(0.498)$ \\
\hline part-time university & -0.259 & $*$ & $(0.146)$ & 0.032 & & $(0.187)$ & -0.529 & $*$ & $(0.273)$ \\
\hline tenure & 0.467 & $* * *$ & $(0.139)$ & 0.776 & $* * *$ & $(0.291)$ & 2.032 & $* *$ & $(0.861)$ \\
\hline group exact sc. & 0.323 & & $(0.235)$ & 0.332 & & $(0.381)$ & 0.185 & & $(0.733)$ \\
\hline group humanities & 0.554 & $* *$ & $(0.240)$ & 0.706 & $* *$ & $(0.355)$ & 1.457 & $* *$ & $(0.645)$ \\
\hline group other & 0.251 & & $(0.426)$ & 1.231 & $* *$ & $(0.509)$ & 2.016 & $* *$ & $(1.013)$ \\
\hline \multicolumn{10}{|l|}{ Duration } \\
\hline age at entry & -0.031 & $* * *$ & $(0.011)$ & -0.051 & $* * *$ & $(0.016)$ & -0.073 & $* * *$ & $(0.026)$ \\
\hline duration rank 0 & -0.037 & $* * *$ & $(0.011)$ & -0.062 & $* * *$ & $(0.014)$ & -0.114 & $* * *$ & $(0.025)$ \\
\hline duration rank 1 & & & & -0.115 & $* * *$ & $(0.033)$ & -0.192 & $* * *$ & $(0.067)$ \\
\hline duration rank 2 & & & & & & & -0.224 & $* * *$ & $(0.060)$ \\
\hline \multicolumn{10}{|l|}{ Performance Measures } \\
\hline highest duty & -0.107 & & $(0.214)$ & 0.088 & & $(0.066)$ & -0.078 & & $(0.087)$ \\
\hline number of duty & 0.643 & & $(0.967)$ & -0.066 & & $(0.229)$ & 0.683 & $* *$ & $(0.315)$ \\
\hline \multicolumn{10}{|l|}{ Exact Sciences } \\
\hline teaching load & 0.115 & $* * *$ & $(0.035)$ & 0.071 & $* * *$ & $(0.027)$ & 0.126 & $* * *$ & $(0.041)$ \\
\hline SCIE publication & 0.059 & & $(0.043)$ & 0.196 & $* * *$ & $(0.039)$ & 0.147 & $* * *$ & $(0.042)$ \\
\hline SCIE impact factor & 0.221 & $* * *$ & $(0.054)$ & 0.115 & $* *$ & $(0.056)$ & 0.109 & & $(0.086)$ \\
\hline SSCI publication & 0.845 & & $(0.940)$ & 2.321 & & $(1.653)$ & 0.409 & & $(2.638)$ \\
\hline SSCI impact factor & 0.162 & & $(1.610)$ & -0.073 & & $(1.897)$ & -0.412 & & $(2.209)$ \\
\hline Proceedings & 0.599 & $* * *$ & $(0.170)$ & 0.264 & $* * *$ & $(0.090)$ & 0.107 & & $(0.083)$ \\
\hline \multicolumn{10}{|l|}{ Humanities } \\
\hline teaching load & 0.144 & $* * *$ & $(0.036)$ & 0.125 & $* * *$ & $(0.036)$ & 0.042 & & $(0.053)$ \\
\hline SCIE publication & 0.880 & $* *$ & $(0.443)$ & 1.066 & $* *$ & $(0.454)$ & 0.506 & & $(0.361)$ \\
\hline SCIE impact factor & 0.119 & & $(0.277)$ & -0.538 & $*$ & $(0.290)$ & 0.176 & & $(0.273)$ \\
\hline SSCI publication & 1.114 & $* * *$ & $(0.396)$ & 0.831 & $* * *$ & $(0.260)$ & 0.998 & $* *$ & $(0.427)$ \\
\hline SSCI impact factor & -0.550 & & $(0.415)$ & -0.107 & & $(0.247)$ & -0.792 & $*$ & $(0.437)$ \\
\hline Proceedings & -1.731 & & $(1.124)$ & 1.017 & & $(0.676)$ & 2.321 & $* *$ & $(0.923)$ \\
\hline \multicolumn{10}{|l|}{ Medical Sciences } \\
\hline teaching load & 0.199 & $* * *$ & $(0.039)$ & 0.207 & $* * *$ & $(0.040)$ & 0.111 & $* *$ & $(0.052)$ \\
\hline SCIE publication & 0.155 & $* * *$ & $(0.025)$ & 0.164 & $* * *$ & $(0.027)$ & 0.029 & & $(0.021)$ \\
\hline SCIE impact factor & 0.135 & $* * *$ & $(0.023)$ & 0.105 & $* * *$ & $(0.029)$ & 0.227 & $* * *$ & $(0.048)$ \\
\hline SSCI publication & 0.530 & & $(0.602)$ & 1.853 & $*$ & $(0.958)$ & -0.119 & & $(0.655)$ \\
\hline SSCI impact factor & 0.235 & & $(0.418)$ & -0.255 & & $(0.540)$ & 1.917 & $* *$ & $(0.806)$ \\
\hline Proceedings & 0.286 & & $(0.279)$ & -0.244 & & $(0.328)$ & 1.404 & $* * *$ & $(0.380)$ \\
\hline Baseline Dummies & YES & & & YES & & & YES & & \\
\hline Rank Cohort Dummies & YES & & & YES & & & YES & & \\
\hline Observations Number & 4295 & & & 3364 & & & 1939 & & \\
\hline $\mathrm{df}$ & 58 & & & 58 & & & 61 & & \\
\hline 11 & -1387 & & & -967.4 & & & -468.6 & & \\
\hline
\end{tabular}

Note: The empirical results are based on the logistic discrete time hazard rate model (1), as in Table 8 . The only difference is that each regression now also includes performance measures. Standard errors are in parentheses. Coefficient significance is denoted using asterisks: ${ }^{* * *}$ is $\mathrm{p}<0.01,{ }^{* *}$ is $\mathrm{p}<0.05$, and ${ }^{*}$ is $\mathrm{p}<0.1$ 


\section{Table 10: Conditional Logit Tournament Model - Including Performance Measures}

\begin{tabular}{|c|c|c|c|c|c|c|c|c|c|}
\hline & \multicolumn{3}{|c|}{$\begin{array}{c}\text { Promotion to } \\
\text { Rank } 2\end{array}$} & \multicolumn{3}{|c|}{$\begin{array}{c}\text { Promotion to } \\
\text { Rank } 3\end{array}$} & \multicolumn{3}{|c|}{$\begin{array}{c}\text { Promotion to } \\
\text { Rank } 4\end{array}$} \\
\hline & Coef. & & Std.Err. & Coef. & & Std.Err. & Coef. & & Std.Err \\
\hline \multicolumn{10}{|l|}{ Individual and Contract } \\
\hline \multicolumn{10}{|l|}{ Characteristics } \\
\hline female & -0.247 & $*$ & $(0.127)$ & 0.041 & & $(0.173)$ & -0.632 & $* *$ & $(0.260)$ \\
\hline foreign & 0.013 & & $(0.277)$ & -0.454 & & $(0.337)$ & 0.187 & & $(0.531)$ \\
\hline Ph.D. same country & 0.039 & & $(0.244)$ & -0.936 & $* * *$ & $(0.326)$ & -0.527 & & $(0.495)$ \\
\hline Ph.D. world & 0.391 & & $(0.250)$ & -0.285 & & $(0.248)$ & 0.169 & & $(0.405)$ \\
\hline external entrant & 0.156 & & $(0.202)$ & 0.832 & $* * *$ & $(0.265)$ & -0.265 & & $(0.370)$ \\
\hline rank 2 entrant & & & & -0.914 & $* * *$ & $(0.205)$ & -0.470 & & $(0.325)$ \\
\hline rank 3 entrant & & & & & & & -1.353 & $* * *$ & $(0.493)$ \\
\hline part-time university & -0.272 & $*$ & $(0.143)$ & 0.078 & & $(0.189)$ & -0.573 & $* *$ & $(0.276)$ \\
\hline tenure & 0.497 & $* * *$ & $(0.136)$ & 0.622 & $* *$ & $(0.283)$ & 2.453 & $* * *$ & $(0.880)$ \\
\hline \multicolumn{10}{|l|}{ Duration } \\
\hline age at entry & -0.035 & $* * *$ & $(0.011)$ & -0.054 & $* * *$ & $(0.016)$ & -0.084 & $* * *$ & $(0.026)$ \\
\hline duration rank 0 & -0.035 & $* * *$ & $(0.011)$ & -0.068 & $* * *$ & $(0.014)$ & -0.097 & $* * *$ & $(0.024)$ \\
\hline duration rank 1 & & & & -0.096 & $* * *$ & $(0.033)$ & -0.202 & $* * *$ & $(0.069)$ \\
\hline duration rank 2 & & & & & & & -0.225 & $* * *$ & $(0.059)$ \\
\hline \multicolumn{10}{|l|}{ Performance Measures } \\
\hline highest duty & -0.048 & & $(0.220)$ & 0.095 & & $(0.068)$ & -0.095 & & $(0.087)$ \\
\hline number of duty & 0.324 & & $(0.996)$ & -0.052 & & $(0.238)$ & 0.694 & $* *$ & $(0.313)$ \\
\hline \multicolumn{10}{|l|}{ Exact Sciences } \\
\hline teaching load & 0.125 & $* * *$ & $(0.037)$ & 0.082 & $* * *$ & $(0.027)$ & 0.138 & $* * *$ & $(0.039)$ \\
\hline SCIE publication & 0.083 & $*$ & $(0.045)$ & 0.196 & $* * *$ & $(0.040)$ & 0.148 & $* * *$ & $(0.041)$ \\
\hline SCIE impact factor & 0.204 & $* * *$ & $(0.055)$ & 0.144 & $* *$ & $(0.056)$ & 0.124 & & $(0.087)$ \\
\hline SSCI publication & 0.847 & & $(0.956)$ & 1.949 & & $(1.633)$ & 0.554 & & $(3.281)$ \\
\hline SSCI impact factor & -0.040 & & $(1.678)$ & 0.245 & & $(1.856)$ & -0.590 & & $(2.873)$ \\
\hline Proceedings & 0.494 & $* * *$ & $(0.172)$ & 0.297 & $* * *$ & $(0.094)$ & 0.112 & & $(0.083)$ \\
\hline \multicolumn{10}{|l|}{ Humanities } \\
\hline teaching load & 0.145 & $* * *$ & $(0.037)$ & 0.108 & $* * *$ & $(0.038)$ & 0.059 & & $(0.056)$ \\
\hline SCIE publication & 0.845 & $*$ & $(0.442)$ & 1.133 & $* * *$ & $(0.435)$ & 0.397 & & $(0.329)$ \\
\hline SCIE impact factor & 0.126 & & $(0.281)$ & -0.517 & $*$ & $(0.285)$ & 0.220 & & $(0.245)$ \\
\hline SSCI publication & 1.200 & $* * *$ & $(0.398)$ & 0.701 & $* *$ & $(0.276)$ & 0.807 & $*$ & $(0.416)$ \\
\hline SSCI impact factor & -0.630 & & $(0.419)$ & -0.036 & & $(0.258)$ & -0.637 & & $(0.441)$ \\
\hline Proceedings & -1.930 & & $(1.143)$ & 0.825 & & $(0.678)$ & 1.681 & * & $(0.951)$ \\
\hline \multicolumn{10}{|l|}{ Medical Sciences } \\
\hline teaching load & 0.202 & $* * *$ & $(0.039)$ & 0.207 & $* * *$ & $(0.040)$ & 0.088 & & $(0.053)$ \\
\hline SCIE publication & 0.150 & $* * *$ & $(0.026)$ & 0.141 & $* * *$ & $(0.027)$ & 0.059 & $* *$ & $(0.024)$ \\
\hline SCIE impact factor & 0.134 & $* * *$ & $(0.023)$ & 0.113 & $* * *$ & $(0.030)$ & 0.204 & $* * *$ & $(0.048)$ \\
\hline SSCI publication & 0.556 & & $(0.633)$ & 1.776 & $*$ & $(1.026)$ & 0.521 & & $(0.609)$ \\
\hline SSCI impact factor & 0.162 & & $(0.428)$ & -0.100 & & $(0.553)$ & 1.513 & $* *$ & $(0.692)$ \\
\hline Proceedings & 0.221 & & $(0.283)$ & -0.027 & & $(0.320)$ & 1.364 & $* * *$ & $(0.394)$ \\
\hline Baseline Dummies & YES & & & YES & & & YES & & \\
\hline Rank Cohort Dummies & $\mathrm{NO}$ & & & NO & & & $\mathrm{NO}$ & & \\
\hline Observations Number & 4170 & & & 3419 & & & 1824 & & \\
\hline df & 37 & & & 39 & & & 41 & & \\
\hline 11 & -1226 & & & -839.2 & & & -388.1 & & \\
\hline
\end{tabular}

Note: The empirical results are based on the conditional logit "tournament" model (3), with $K_{t}$ chosen alternatives and $J_{t}-K_{t}$ non-chosen alternatives per tournament $t$. The data sets and covariates of the complete model are used, but group membership dummies and rank cohort dummies are excluded. Standard errors are in parentheses. Coefficient significance is denoted using asterisks: ${ }^{* * *}$ is $\mathrm{p}<0.01,{ }^{*} *$ is $\mathrm{p}<0.05$, and $*$ is $\mathrm{p}<0.1$ 


\section{Figures}

Figure 1: The Late Beginner Property

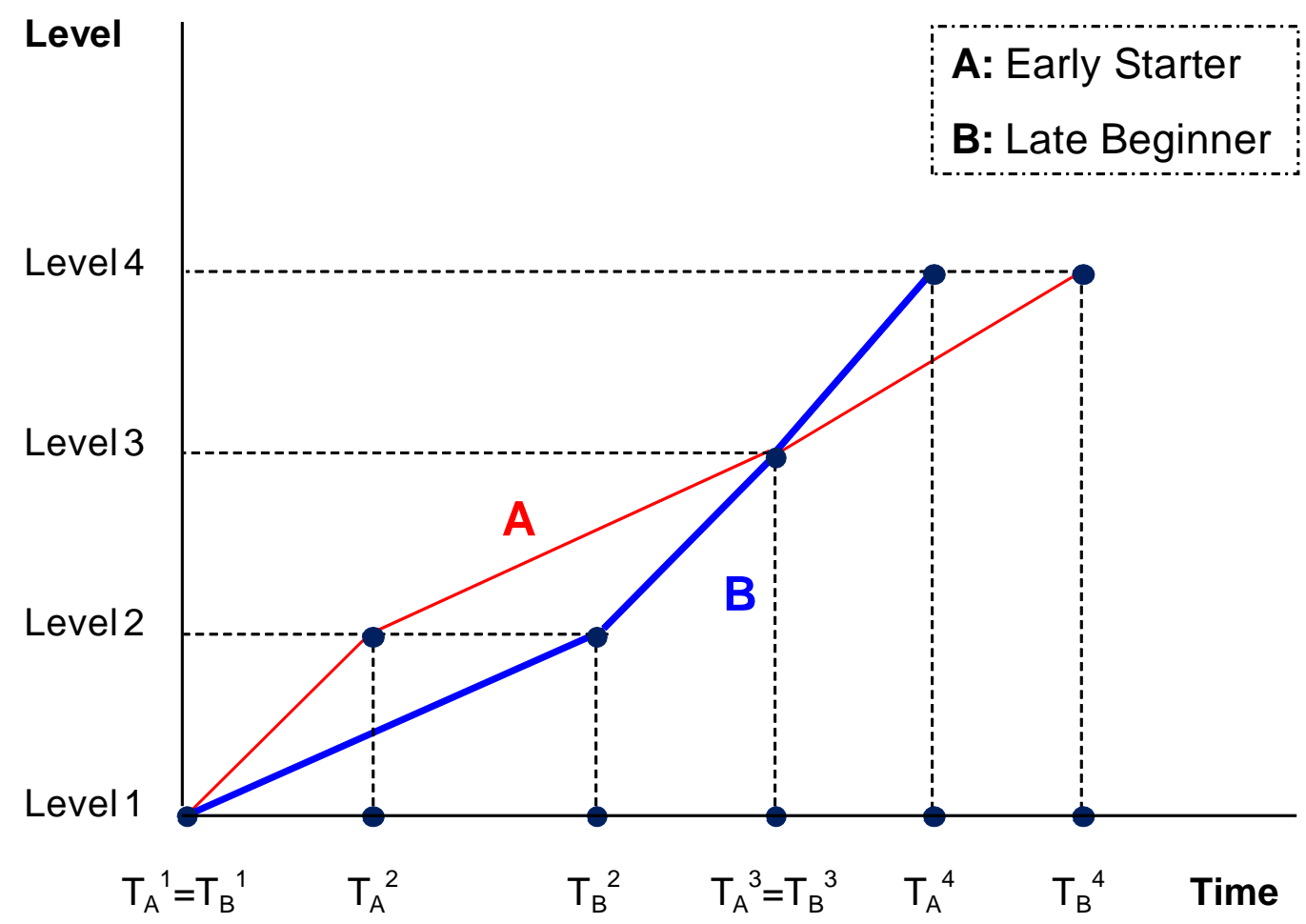

Note: This figure is a modified version of the figure first presented by Chiappori et al. (1999). Worker A is the early starter, reaching level 2 first. Worker B is the late beginner, able to catch up with worker A by level 3. The late beginner property predicts that worker B (the late beginner) will be promoted more quickly in the future (to level 4). 
Figure 2: Evolution of THE NUMBER OF PROFESSORS

IN THE UNIVERSITY AND WITHIN EACH GROUP

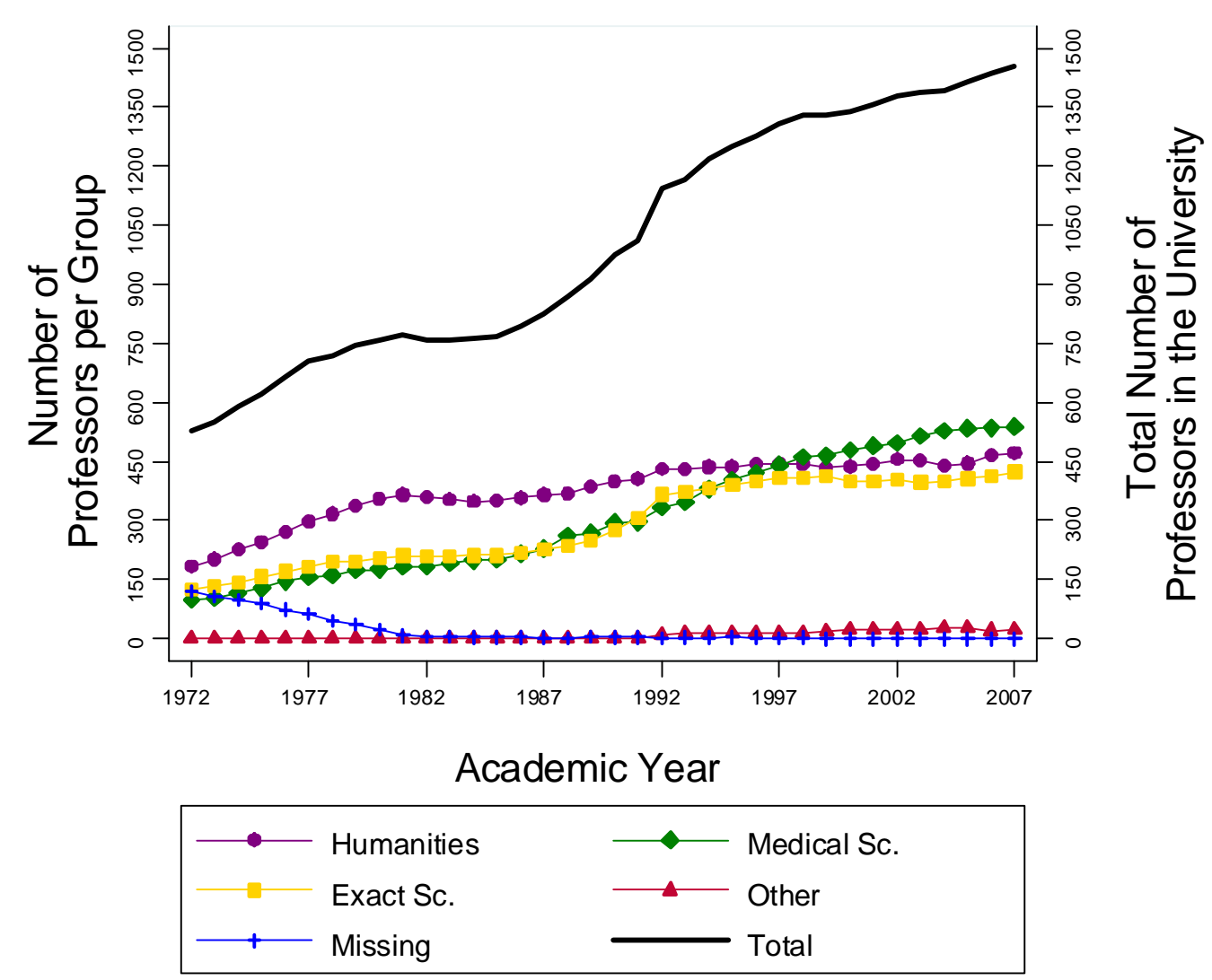

Note: Shows the evolution of the total number of professors (right axis and bold continuous line) and the evolution broken down by the three university groups (left axis and dotted lines). 
Figure 3: Structural Stability

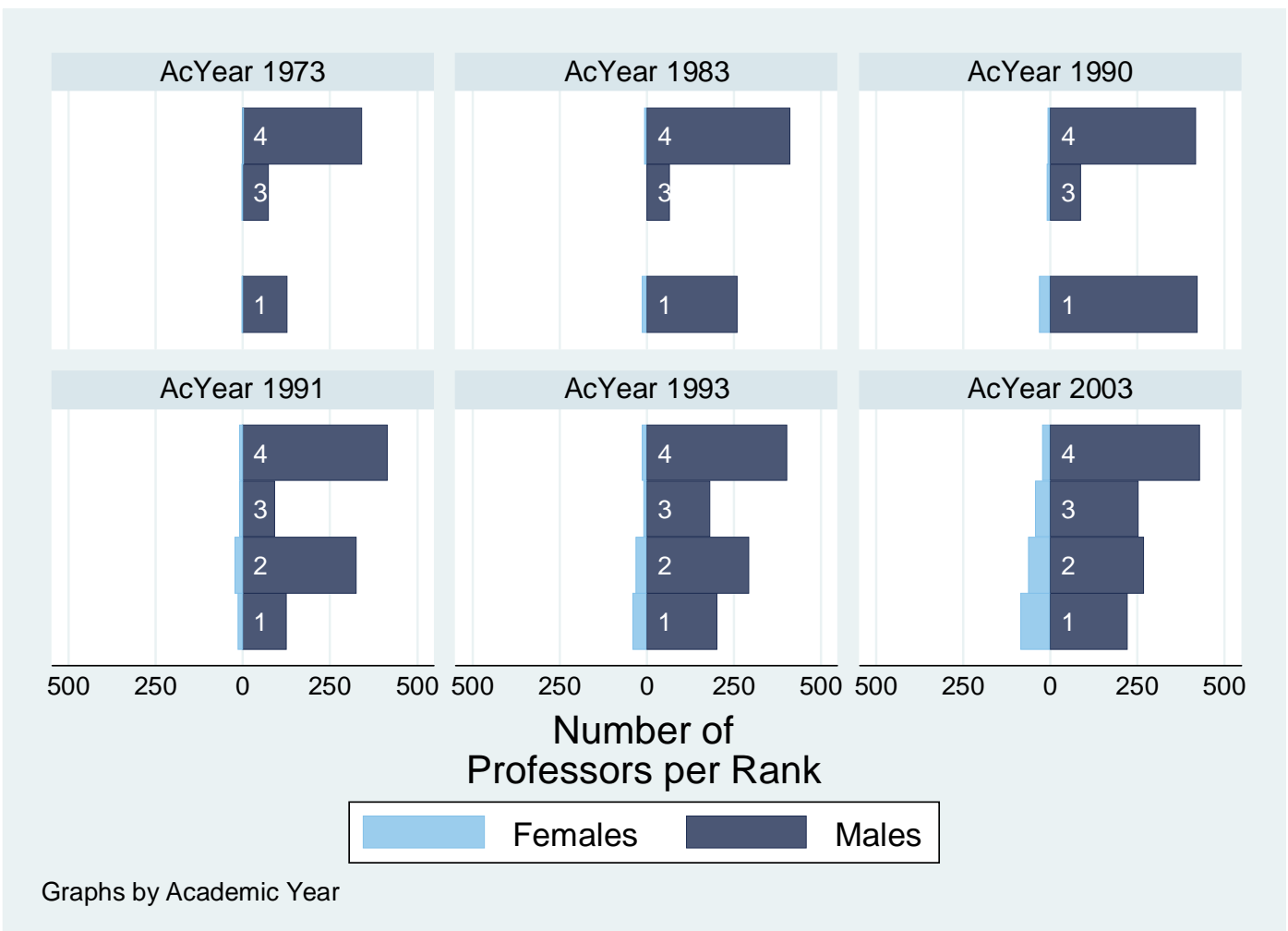

Note: Shows the structure of the hierarchy at different points in time by gender. Comparison of the top panel and the bottom panel reveals the 1991 reform in the ranking system with the addition of rank 2. Within the subperiods 1972-1990 (top panel) and 1991-2007 (bottom panel) the hierarchy is relatively stable. 
Figure 4: WAGE SCALES AND WAGE PATH WITH PROMOTION EVERY 5 YEARS

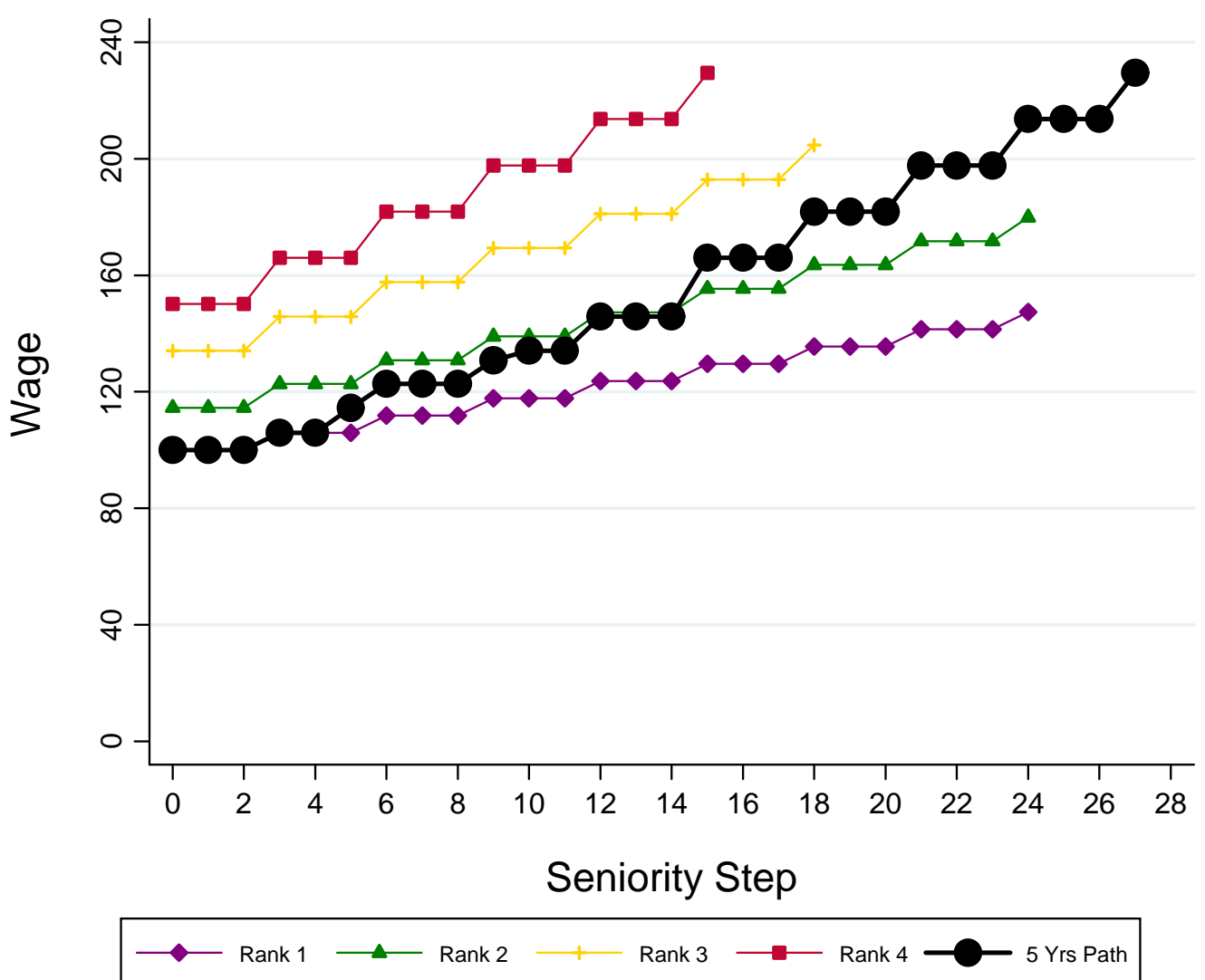

Note: Each non bold line is a different salary scale, one for each of the four professorship ranks. The salary of a professor in rank 1 with zero years of seniority is normalized to 100 . The bold line shows the career progression of a professor entering the university in rank 1 and being promoted every 5 years. 
Figure 5: Promotion Hazard Rates By Rank

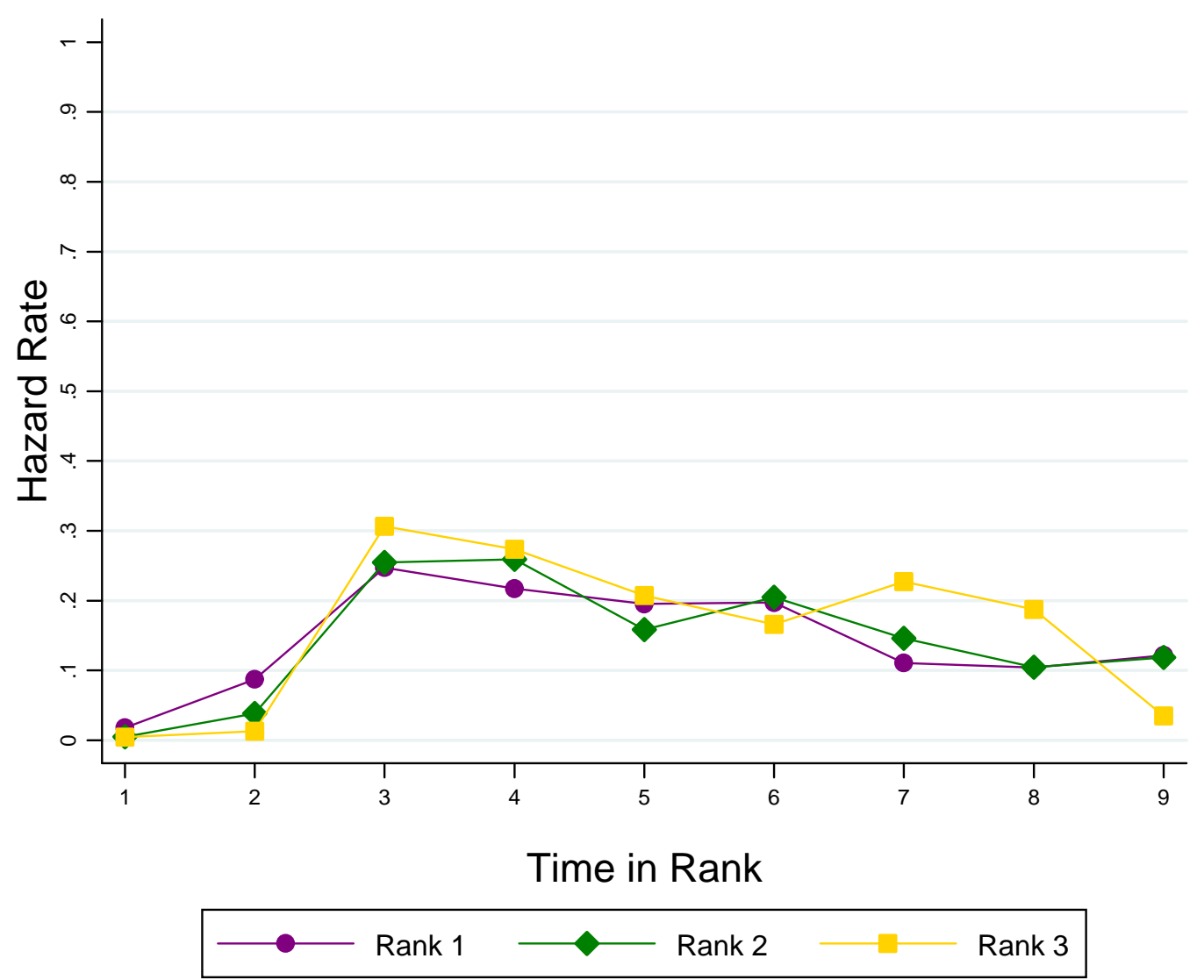

Note: Promotion hazard rates by rank estimated using the complete model for a representative individual with average characteristics.

\section{Appendix. Further data analysis}

We first present further descriptive information on the university and its personnel policies. We subsequently present the econometric results of the promotion hazard rate model in terms of the marginal effects of the explanatory variables on the promotion hazard rate (rather than in terms of the underlying parameters). 


\subsection{Further descriptive statistics}

Table A.1 provides more detail on the summary statistics presented earlier in Table 2. In addition to showing the number of observations and the means for the full period 1972-2007 and the most recent subperiod 1991-2007, it now also presents the information for the older subperiods 1972-1979 and 1980-1990.

Table A. 1: Summary statistics

\begin{tabular}{|c|c|c|c|c|c|c|c|c|}
\hline \multirow{2}{*}{\multicolumn{9}{|c|}{ Number of }} \\
\hline & & & & & & & & \\
\hline Observations & \multicolumn{2}{|l|}{36,284} & \multicolumn{2}{|l|}{5,126} & \multicolumn{2}{|l|}{8,961} & \multicolumn{2}{|l|}{22,197} \\
\hline Professors & \multicolumn{2}{|l|}{2691} & \multicolumn{2}{|l|}{861} & \multicolumn{2}{|l|}{1231} & \multicolumn{2}{|l|}{2282} \\
\hline $\begin{array}{l}\text { Variables } \\
\text { Individual and Contract } \\
\text { Characteristics }\end{array}$ & Obs & Mean & Obs & Mean & Obs & Mean & Obs & Mean \\
\hline Age & 36,284 & 48.73 & 5,126 & 47.41 & 8,961 & 49.09 & 22,197 & 48.89 \\
\hline Female & 36,284 & 0.09 & 5,126 & 0.02 & 8,961 & 0.03 & 22,197 & 0.13 \\
\hline Foreign & 36,284 & 0.04 & 5,126 & 0.05 & 8,961 & 0.03 & 22,197 & 0.04 \\
\hline Ph.D. own university & 22,950 & 0.86 & 1,439 & 0.90 & 4,441 & 0.88 & 17,070 & 0.85 \\
\hline Ph.D. same country & 22,950 & 0.06 & 1,439 & 0.07 & 4,441 & 0.07 & 17,070 & 0.06 \\
\hline Ph.D. world & 22,950 & 0.08 & 1,439 & 0.03 & 4,441 & 0.05 & 17,070 & 0.09 \\
\hline External Entrant & 36,284 & 0.18 & 5,126 & 0.31 & 8,961 & 0.21 & 22,197 & 0.15 \\
\hline Rank 1 Entrant & 36,284 & 0.87 & 5,126 & 0.82 & 8,961 & 0.91 & 22,197 & 0.86 \\
\hline Rank 2 Entrant & 36,284 & 0.06 & 5,126 & - & 8,961 & - & 22,197 & 0.10 \\
\hline Rank 3 Entrant & 36,284 & 0.04 & 5,126 & 0.09 & 8,961 & 0.05 & 22,197 & 0.02 \\
\hline Rank 4 Entrant & 36,284 & 0.03 & 5,126 & 0.09 & 8,961 & 0.04 & 22,197 & 0.01 \\
\hline Rank 1 & 36,284 & 0.27 & 5,126 & 0.29 & 8,961 & 0.40 & 22,197 & 0.22 \\
\hline Rank 2 & 36,284 & 0.16 & na & na & na & na & 22,197 & 0.26 \\
\hline Rank 3 & 36,284 & 0.15 & 5,126 & 0.11 & 8,961 & 0.10 & 22,197 & 0.19 \\
\hline Rank 4 & 36,284 & 0.41 & 5,126 & 0.60 & 8,961 & 0.51 & 22,197 & 0.33 \\
\hline Part-time university & 35,175 & 0.30 & 5,007 & 0.27 & 8,666 & 0.25 & 21,502 & 0.33 \\
\hline Tenure & 36,277 & 0.84 & 5,119 & 0.82 & 8,961 & 0.83 & 22,197 & 0.85 \\
\hline Seniority & 28,148 & 9.89 & 3,505 & 5.37 & 5,766 & 6.60 & 18,877 & 11.73 \\
\hline Medical Sciences Grp. & 35,547 & 0.31 & 4,486 & 0.24 & 8,888 & 0.27 & 22,173 & 0.35 \\
\hline Exact Sciences Grp. & 35,547 & 0.29 & 4,486 & 0.29 & 8,888 & 0.28 & 22,173 & 0.30 \\
\hline Humanities Grp. & 35,547 & 0.38 & 4,486 & 0.46 & 8,888 & 0.45 & 22,173 & 0.34 \\
\hline Other Grp. & 35,547 & 0.01 & 4,486 & 0.00 & 8,888 & 0.00 & 22,173 & 0.01 \\
\hline \multicolumn{9}{|l|}{ Duration Variables } \\
\hline Age at entry & 36,284 & 30.65 & 5,126 & 34.42 & 8,961 & 32.04 & 22,197 & 29.21 \\
\hline Duration - rank 0 & 36,284 & 6.39 & 5,126 & 3.93 & 8,961 & 5.20 & 22,197 & 7.45 \\
\hline Duration - rank 1 & 36,284 & 4.07 & 5,126 & 2.95 & 8,961 & 4.58 & 22,197 & 4.12 \\
\hline Duration - rank 2 & 36,284 & 1.22 & 5,126 & 0.00 & 8,961 & 0.00 & 22,197 & 2.00 \\
\hline Duration - rank 3 & 36,284 & 1.67 & 5,126 & 1.32 & 8,961 & 1.49 & 22,197 & 1.83 \\
\hline Duration - rank 4 & 36,284 & 4.68 & 5,126 & 5.58 & 8,961 & 6.22 & 22,197 & 3.86 \\
\hline \multicolumn{9}{|l|}{ Performance Measures } \\
\hline Highest Duty & 31,158 & 1.11 & - & - & 8,961 & 1.21 & 22,197 & 1.07 \\
\hline Number of Duty & 31,158 & 0.31 & - & - & 8,961 & 0.33 & 22,197 & 0.31 \\
\hline Teaching Load & 31,158 & 5.08 & - & - & 8,961 & 6.25 & 22,197 & 4.61 \\
\hline SCIE Publication & 20,741 & 2.52 & - & - & - & - & 20,741 & 2.52 \\
\hline SCIE Impact Factor & 20,741 & 2.02 & - & - & - & - & 20,741 & 2.02 \\
\hline SSCI Publication & 13,669 & 0.12 & - & - & - & - & 13,669 & 0.12 \\
\hline SSCI Impact Factor & 13,669 & 0.11 & - & - & - & - & 13,669 & 0.11 \\
\hline Proceedings & 14,947 & 0.27 & - & - & - & - & 14,947 & 0.27 \\
\hline
\end{tabular}


Evolution of individual characteristics Figure A.1 presents the evolution of several individual characteristics (which are time-invariant individual characteristics, in contrast with the performance variables discussed further below). The share of non-foreign professors has remained remarkably high, fluctuating only slightly around the average of $96 \%$ during the entire period. The share of female professors has substantially increased especially since the late 1980s, going from less than 1\% in 1972 to approximatively $20 \%$ in 2007 . The relative importance of professors with a $\mathrm{Ph} . \mathrm{D}$. from this university has gradually decreased over time but it remains fairly high at more than $80 \%$.

Figure A. 1: Evolution of time-INVARIANt VARIABLES

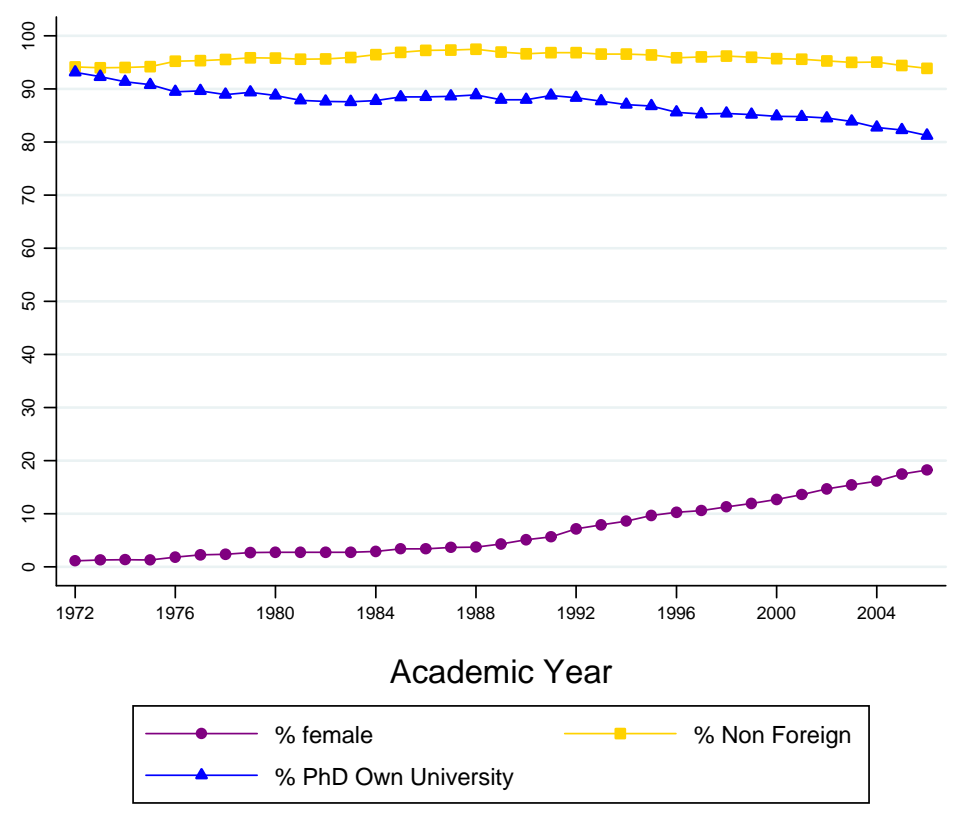


Evolution of performance characteristics Figure A.2 shows the evolution of teaching load and Figure A.3 shows the evolution of research performance (both of which are evidently time-varying individual characteristics). Recall that teaching load information is only available since 1980 and research performance information is only available since 1991.

Figure A.2 shows the average teaching load per professor, measured as the number of week-hours, with one week-hour corresponding to 26-30 hours of teaching per year. It remained stable at large levels during 1980-1986, and it then gradually decreased to stable levels during 1992-2003. It increased again in 2004 and 2005, presumably due to the Bachelor-Master reforms. Since 1992, the average teaching load has been substantially lower in medical sciences than in exact sciences and humanities.

\section{Figure A. 2: Evolution of TEACHing LOAD}

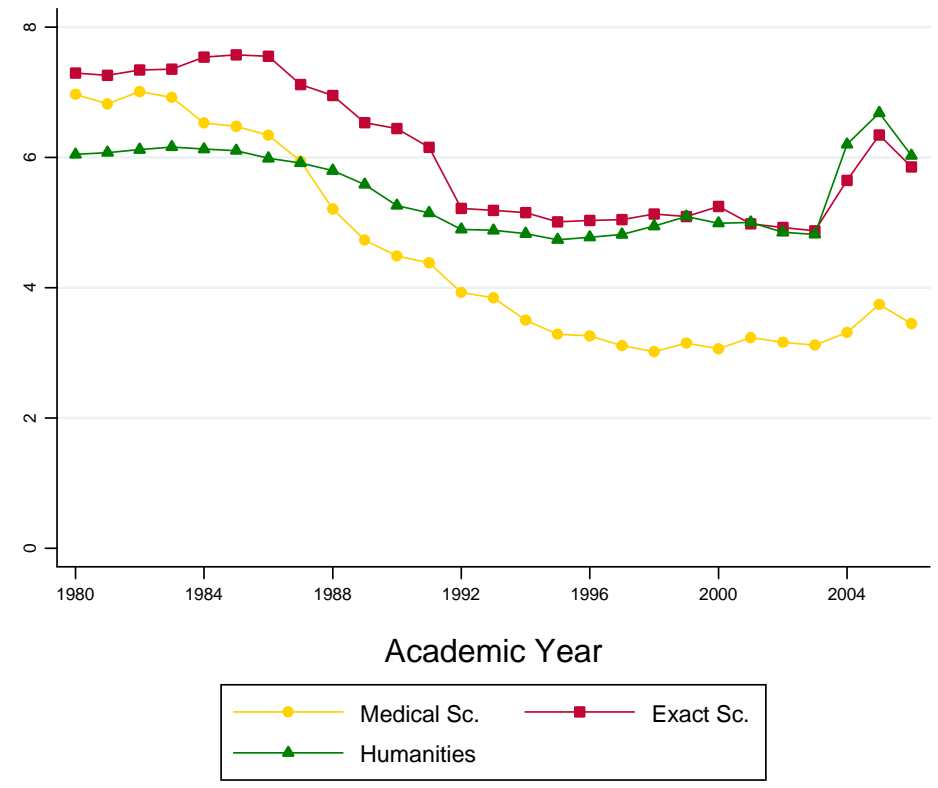

Figure A.3 displays publication information for SCIE, SSCI and Proceedings measures. The top panel shows the trend of the SCIE measures by group. The bottom panel shows the trend of SSCI and Proceedings.

The top panel shows that in medical sciences the average quality of publications (impact) has increased more strongly than the average quantity of publications over the last 16 years. In exact sciences, the reverse seems true: the average quantity of publications has increased more rapidly than the average quality (impact). By 2007 the researchers of both groups were publishing a similar number of papers on average, but the average impact factor of 
researchers in medical sciences remained higher. In humanities, the number of publications and impact factor in SCIE has been more or less stable at low levels over the entire period.

The bottom panel of Figure A.3 shows that SSCI performance is mainly relevant to the humanities group, and both the quantity and quality has been steadily increasing over the period for this group. Proceedings are only relevant to exact sciences and this has also been steadily increasing for this group. 
Figure A. 3: Evolution of PUblication AND impact FACTOR VARiables

Medical Sc.

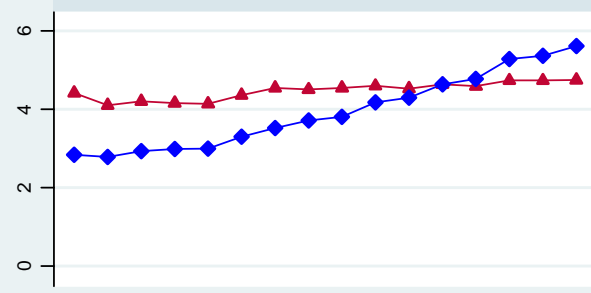

Humanities

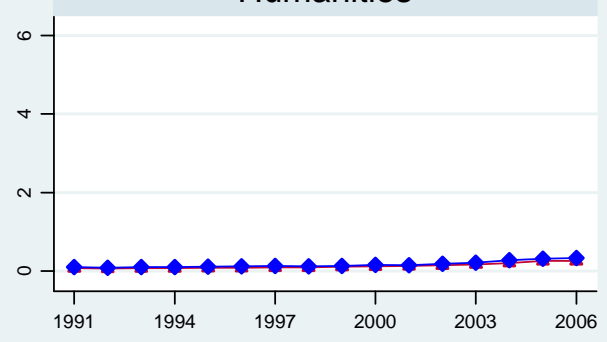

Exact Sc.

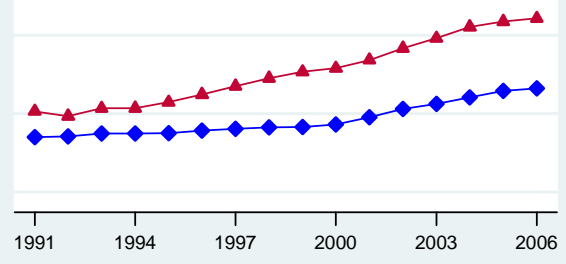

Academic Year

Graphs by University Group
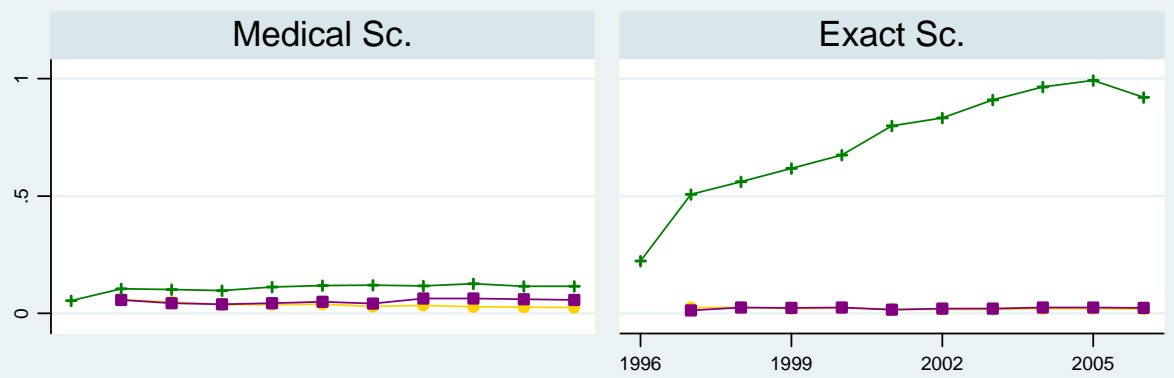

Humanities

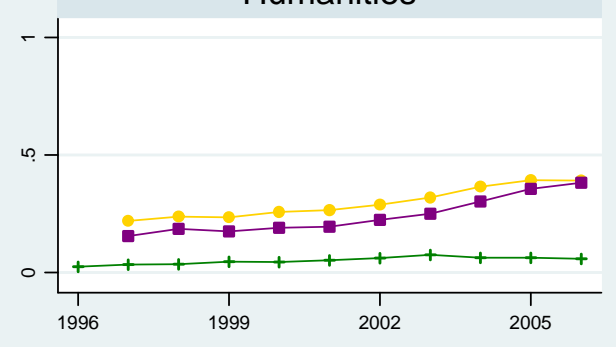

\section{Academic Year}

\begin{tabular}{|lll|}
\hline SSCI Publication & SSCI Impact Factor $\longrightarrow$ Proceedings \\
\hline Graphs by University Group & 50
\end{tabular}


Evolution of entry age in rank The entry age in rank is the age at which a professor enters the rank, either as a new hire or through promotion from a previous rank.

Figure A.4 shows that average entry age in rank 1 and rank 2 are very stable across the entire time period. Entry age in rank 3 and 4 follow a somewhat more erratic pattern before 1992, but are also stable afterwards. In contrast with Rosenblum and Rubin Rosenblum (1990), we do not find that entry age into the internal labor market has been increasing in time.

The entry age in rank appear somewhat high. This is because we report average entry age and the distribution is quite skewed. The median entry ages in rank are considerably lower.

Figure A. 4: ENTRY AGE IN RANK

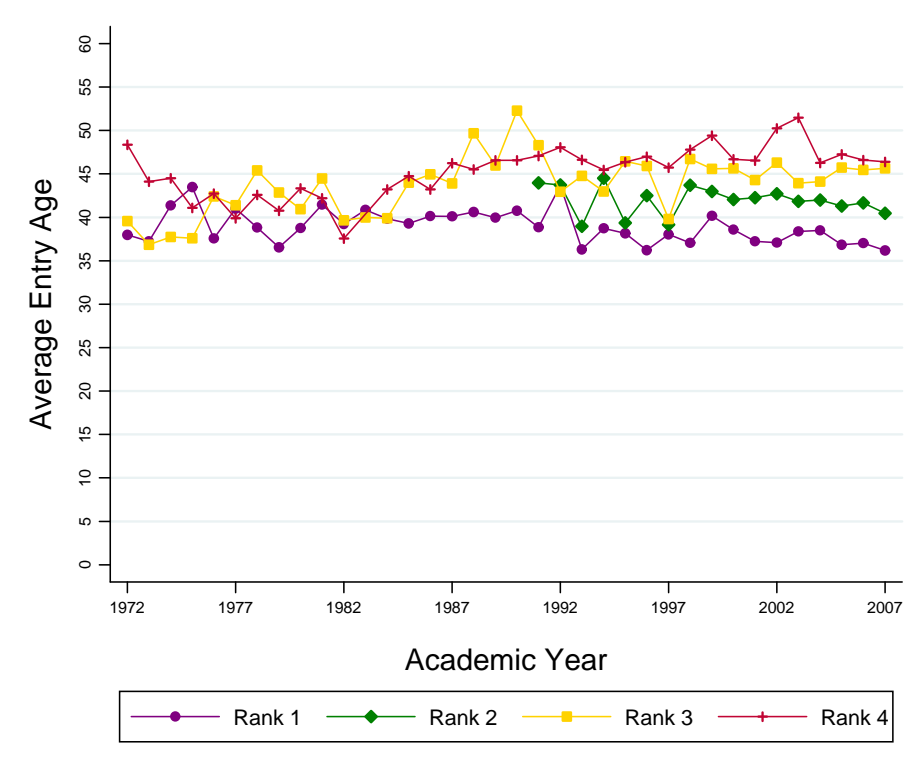

Further transition matrices Table A.2 extends the earlier transition matrix of Table A.2 in the main text. It now also shows the transition matrix for the first subperiod 1972-1990, in addition to the transition matrix for the period 1991-2006 shown earlier. 
Table A. 2: Professorship Transition Matrices

Academic Year 1972 to 1990 incl.

\begin{tabular}{l|cccccc|ccc|c} 
& \multicolumn{1}{|c}{ Rank 1 } & Rank 2 & Rank 3 & Rank 4 & Out & $\begin{array}{c}\text { Total } \\
\text { Exit }\end{array}$ & $\begin{array}{c}\text { Early } \\
\text { Exit }\end{array}$ & $\begin{array}{c}\text { Early } \\
\text { Retire }\end{array}$ & Retire & Total \\
\hline \hline Int. Entry & 648 & 33 & 5 & 8 & - & - & - & - & - & 694 \\
Delayed Int. Entry & 67 & 5 & 1 & 1 & - & - & - & - & - & 74 \\
Ext. Entry & 97 & 6 & 5 & 17 & - & - & - & - & - & 125 \\
\hline Total Entry & 812 & 44 & 11 & 26 & - & - & - & - & - & 893 \\
Rank 1 & 4230 & 309 & 261 & 128 & 111 & 5 & 53 & 14 & 44 & 5044 \\
Rank 2 & 0 & 2 & 0 & 1 & 0 & 0 & 0 & 0 & 0 & 3 \\
Rank 3 & 1 & 0 & 1149 & 226 & 26 & 1 & 1 & 6 & 19 & 1403 \\
Rank 4 & 0 & 0 & 8 & 7340 & 271 & 9 & 28 & 34 & 209 & 7628 \\
Temp Out & 5 & 0 & 1 & 8 & 0 & 32 & 0 & 0 & 0 & 46 \\
\hline Total & 5048 & 355 & 1430 & 7729 & 408 & 47 & 82 & 54 & 272 & 15017
\end{tabular}

Academic Year 1991 to 2006 incl.

\begin{tabular}{l|rrrrrr|rrr|r} 
& \multicolumn{1}{|c}{ Rank 1 } & Rank 2 & Rank 3 & Rank 4 & Temp & Total & Early & Early \\
Exit & Exit & Retire & Retire & Total \\
\hline \hline Int. Entry & 612 & 130 & 18 & 7 & - & & - & - & - & 767 \\
Delayed Int. Entry & 181 & 38 & 13 & 6 & - & & - & - & - & 238 \\
Ext. Entry & 155 & 54 & 32 & 19 & - & & - & - & - & 260 \\
\hline Total Entry & 948 & 222 & 63 & 32 & - & - & - & - & - & 1,265 \\
Rank 1 & 3,818 & 616 & 7 & 0 & 7 & 151 & 103 & 24 & 24 & 4,599 \\
Rank 2 & 0 & 4,586 & 667 & 12 & 10 & 165 & 57 & 39 & 69 & 5,440 \\
Rank 3 & 0 & 0 & 3,337 & 426 & 1 & 125 & 20 & 35 & 70 & 3,889 \\
Rank 4 & 1 & 0 & 0 & 6,425 & 1 & 386 & 29 & 73 & 284 & 6,813 \\
Temp Out & 7 & 9 & 4 & 3 & 48 & 0 & 0 & 0 & 0 & 71 \\
\hline Total & 4,774 & 5,433 & 4,078 & 6,898 & 67 & 827 & 209 & 171 & 447 & 22,077
\end{tabular}

A graphical representation of the evolution of the transition matrices is shown in Figure 5. We do not distinguish between different types of entry and exit, and we omit the overwhelming number of cases where individuals stay in the same rank. Figure A.5 reveals that the transition process has indeed changed drastically after the reform of 1991. From 1991 onwards, the transition process has become fairly stable. Entry is mainly in rank 1, although an increasing amount of entry in rank 2 takes place in recent years. Promotions are almost always one-rank promotions. Exit mainly takes place at rank 4 . 
Figure A. 5: Sub PERIOds transition matrices
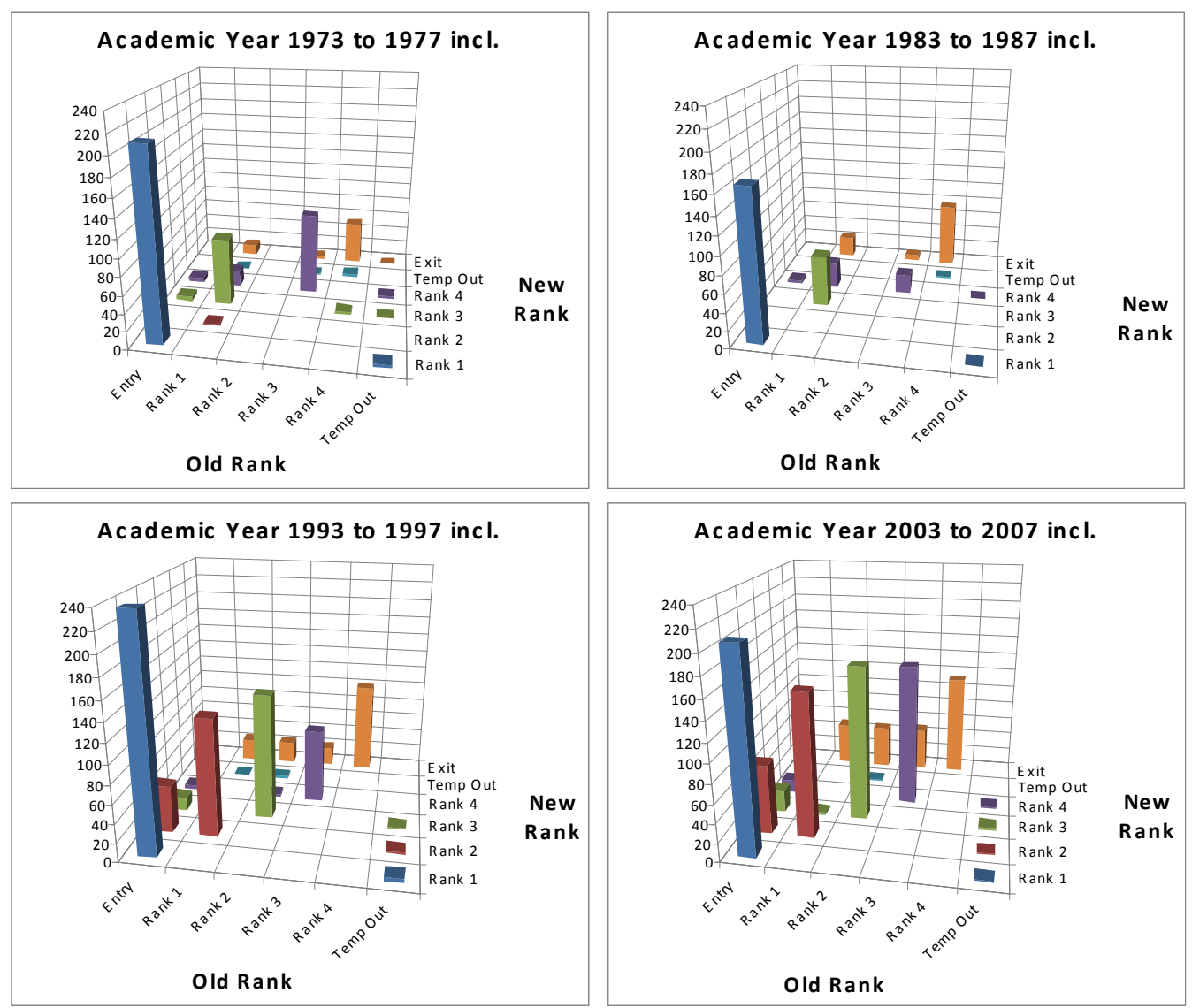


\subsection{Further econometric regressions}

We now present the econometric results of the promotion hazard rate model in terms of the marginal effects of the explanatory variables on the promotion hazard rate, rather than in terms of the underlying parameters. Recall that the promotion hazard rate was given by

$$
h_{j t}^{r}=\frac{1}{1+\exp \left(-\alpha^{r}(t)-v_{j t}^{r}\right)} .
$$

where

$v_{j t}^{r}=\beta_{-1}^{r} A G E_{j}+\beta_{0}^{r} D U R_{j}^{0}+\beta_{1}^{r} D U R_{j}^{1}+\cdots+\beta_{r-2}^{r} D U R_{j}^{r-2}+\beta_{r-1}^{r} D U R_{j}^{r-1}+\gamma^{r} P E R F_{j t}+\delta^{r} O T H E R$.

Tables 8 and 9 directly presented the estimated parameters $\beta, \gamma$ and $\delta$. This had the advantage of a good comparability with the estimates of the tournament promotion model in 10 . The two tables below will present the results in terms of the marginal effects on the hazard rate. So for a continuous variables such as $P E R F_{j t}$ we compute

$$
\begin{aligned}
\frac{\partial h_{j t}}{\partial P E R F_{j t}} & =\frac{\exp \left(-\alpha^{r}(t)-v_{j t}^{r}\right)}{\left(1+\exp \left(-\alpha^{r}(t)-v_{j t}^{r}\right)\right)^{2}} \gamma^{r} \\
& =h_{j t}\left(1-h_{j t}\right) \gamma^{r}
\end{aligned}
$$

and we average this over all observations. For a discrete variable such as $D U R_{j}^{1}$ we compute the difference between the hazard rate $h_{j t}$ evaluated at $D U R_{j}^{1}+1$ and the hazard rate $h_{j t}$ evaluated at $D U R_{j}^{1}$, and we again average this over all observations.

The two tables below show how the parameter estimates of the earlier Tables 8 and 9 translate in marginal effects on the promotion hazard rate. To illustrate, the table shows that being female reduces the hazard rate of promotion to rank 2 by $2.5 \%$ and to rank 4 by $4.0 \%$. As another example, the hazard rate of promotion to rank 3 is $6 \%$ lower for foreign professors and $6.5 \%$ lower for professors with a Ph.D. from a different university in the same country. 

Table A. 3: Discrete-Time Promotion Hazard Model -
Excluding Performance Measures

\begin{tabular}{|c|c|c|c|c|c|c|}
\hline & \multicolumn{2}{|c|}{$\begin{array}{c}\text { Promotion to } \\
\text { Rank } 2\end{array}$} & \multicolumn{2}{|c|}{$\begin{array}{c}\text { Promotion to } \\
\text { Rank } 3\end{array}$} & \multicolumn{2}{|c|}{$\begin{array}{l}\text { Promotion to } \\
\text { Rank } 4\end{array}$} \\
\hline & $\mathrm{AMF}$ & Std.Err. & $\mathrm{AMF}$ & Std.Err. & $\mathrm{AMF}$ & Std.Err. \\
\hline \\
\hline \multicolumn{7}{|l|}{ Characteristics } \\
\hline female & -0.028 & $(0.013)$ & -0.001 & $(0.015)$ & -0.052 & $(0.022)$ \\
\hline foreign & 0.001 & $(0.028)$ & -0.060 & $(0.025)$ & 0.026 & $(0.045)$ \\
\hline Ph.D. same country & 0.033 & $(0.027)$ & -0.062 & $(0.024)$ & -0.013 & $(0.034)$ \\
\hline Ph.D. world & 0.068 & $(0.034)$ & -0.029 & $(0.021)$ & 0.006 & $(0.030)$ \\
\hline external entrant & 0.006 & $(0.021)$ & 0.088 & $(0.036)$ & -0.027 & $(0.028)$ \\
\hline rank 2 entrant & na & na & -0.065 & $(0.021)$ & -0.045 & $(0.028)$ \\
\hline rank 3 entrant & na & na & na & na & -0.133 & $(0.041)$ \\
\hline part-time university & -0.069 & $(0.018)$ & -0.051 & $(0.017)$ & -0.084 & $(0.027)$ \\
\hline tenure & 0.056 & $(0.016)$ & 0.074 & $(0.022)$ & 0.106 & $(0.038)$ \\
\hline group exact sc. & -0.026 & $(0.014)$ & -0.026 & $(0.016)$ & -0.020 & $(0.020)$ \\
\hline group humanities & -0.027 & $(0.014)$ & -0.030 & $(0.016)$ & -0.019 & $(0.020)$ \\
\hline group other & -0.094 & $(0.029)$ & -0.066 & $(0.034)$ & -0.011 & $(0.074)$ \\
\hline \multicolumn{7}{|l|}{ Duration } \\
\hline age at entry & -0.006 & $(0.001)$ & -0.008 & $(0.002)$ & -0.007 & $(0.003)$ \\
\hline duration rank 0 & -0.005 & $(0.001)$ & -0.007 & $(0.002)$ & -0.010 & $(0.003)$ \\
\hline duration rank 1 & na & na & -0.014 & $(0.004)$ & -0.017 & $(0.006)$ \\
\hline duration rank 2 & na & na & na & na & -0.022 & $(0.007)$ \\
\hline Baseline Dummies & YES & & YES & & YES & \\
\hline Rank Cohort Dummies & YES & & YES & & YES & \\
\hline Observations Number & 4295 & & 3364 & & 1939 & \\
\hline df & 36 & & 36 & & 39 & \\
\hline 11 & -1480 & & -1050 & & -515.7 & \\
\hline
\end{tabular}




\section{Table A. 4: Discrete-Time Promotion Hazard Model - Including Performance Measures}

\begin{tabular}{|c|c|c|c|c|c|c|}
\hline & \multicolumn{2}{|c|}{$\begin{array}{c}\text { Promotion to } \\
\text { Rank } 2\end{array}$} & \multicolumn{2}{|c|}{$\begin{array}{c}\text { Promotion to } \\
\text { Rank } 3\end{array}$} & \multicolumn{2}{|c|}{$\begin{array}{l}\text { Promotion to } \\
\text { Rank } 4\end{array}$} \\
\hline & $\mathrm{AMF}$ & Std.Err. & $\mathrm{AMF}$ & Std.Err. & $\mathrm{AMF}$ & Std.Err. \\
\hline \multicolumn{7}{|l|}{ Individual and Contract } \\
\hline \multicolumn{7}{|l|}{ Characteristics } \\
\hline female & -0.022 & $(0.013)$ & 0.007 & $(0.016)$ & -0.031 & $(0.021)$ \\
\hline foreign & 0.002 & $(0.027)$ & -0.052 & $(0.027)$ & 0.017 & $(0.044)$ \\
\hline Ph.D. same country & 0.009 & $(0.024)$ & -0.068 & $(0.026)$ & -0.064 & $(0.035)$ \\
\hline Ph.D. world & 0.053 & $(0.033)$ & -0.028 & $(0.022)$ & -0.005 & $(0.031)$ \\
\hline external entrant & 0.007 & $(0.020)$ & 0.083 & $(0.036)$ & -0.02 & $(0.028)$ \\
\hline rank 2 entrant & na & na & -0.079 & $(0.025)$ & -0.046 & $(0.029)$ \\
\hline rank 3 entrant & na & na & na & na & -0.113 & $(0.046)$ \\
\hline part-time university & -0.025 & $(0.015)$ & 0.003 & $(0.017)$ & -0.039 & $(0.024)$ \\
\hline tenure & 0.044 & $(0.016)$ & 0.059 & $(0.024)$ & 0.102 & $(0.045)$ \\
\hline group exact sc. & 0.030 & $(0.023)$ & 0.027 & $(0.032)$ & 0.012 & $(0.048)$ \\
\hline group humanities & 0.055 & $(0.027)$ & 0.062 & $(0.034)$ & 0.118 & $(0.065)$ \\
\hline group other & 0.023 & $(0.042)$ & 0.120 & $(0.063)$ & 0.173 & $(0.113)$ \\
\hline \multicolumn{7}{|l|}{ Duration } \\
\hline age at entry & -0.003 & $(0.001)$ & -0.005 & $(0.002)$ & -0.006 & $(0.003)$ \\
\hline duration rank 0 & -0.004 & $(0.001)$ & -0.005 & $(0.002)$ & -0.009 & $(0.003)$ \\
\hline duration rank 1 & na & na & -0.010 & $(0.004)$ & -0.014 & $(0.007)$ \\
\hline duration rank 2 & na & na & na & na & -0.016 & $(0.007)$ \\
\hline \multicolumn{7}{|l|}{ Performance Measures } \\
\hline highest duty & -0.010 & $(0.020)$ & 0.008 & $(0.006)$ & -0.006 & $(0.007)$ \\
\hline number of duty & 0.074 & $(0.128)$ & -0.006 & $(0.020)$ & 0.058 & $(0.035)$ \\
\hline \multicolumn{7}{|l|}{ Exact Sciences } \\
\hline teaching load & 0.011 & $(0.004)$ & 0.006 & $(0.003)$ & 0.009 & $(0.005)$ \\
\hline SCIE publication & 0.005 & $(0.004)$ & 0.016 & $(0.005)$ & 0.011 & $(0.005)$ \\
\hline SCIE impact factor & 0.021 & $(0.007)$ & 0.009 & $(0.005)$ & 0.008 & $(0.007)$ \\
\hline SSCI publication & 0.094 & $(0.126)$ & 0.269 & $(0.235)$ & 0.032 & $(0.223)$ \\
\hline SSCI impact factor & 0.015 & $(0.157)$ & -0.006 & $(0.146)$ & -0.028 & $(0.137)$ \\
\hline Proceedings & 0.063 & $(0.023)$ & 0.022 & $(0.009)$ & 0.008 & $(0.007)$ \\
\hline \multicolumn{7}{|l|}{ Humanities } \\
\hline teaching load & 0.017 & $(0.005)$ & 0.012 & $(0.004)$ & 0.003 & $(0.004)$ \\
\hline SCIE publication & 0.119 & $(0.073)$ & 0.122 & $(0.066)$ & 0.042 & $(0.034)$ \\
\hline SCIE impact factor & 0.014 & $(0.033)$ & -0.043 & $(0.023)$ & 0.014 & $(0.023)$ \\
\hline SSCI publication & 0.158 & $(0.071)$ & 0.091 & $(0.038)$ & 0.087 & $(0.048)$ \\
\hline SSCI impact factor & -0.053 & $(0.036)$ & -0.010 & $(0.022)$ & -0.053 & $(0.031)$ \\
\hline Proceedings & -0.118 & $(0.048)$ & 0.115 & $(0.093)$ & 0.218 & $(0.114)$ \\
\hline \multicolumn{7}{|l|}{ Medical Sciences } \\
\hline teaching load & 0.021 & $(0.006)$ & 0.021 & $(0.006)$ & 0.009 & $(0.005)$ \\
\hline SCIE publication & 0.016 & $(0.004)$ & 0.016 & $(0.004)$ & 0.002 & $(0.002)$ \\
\hline SCIE impact factor & 0.014 & $(0.004)$ & 0.010 & $(0.004)$ & 0.019 & $(0.007)$ \\
\hline SSCI publication & 0.060 & $(0.077)$ & 0.234 & $(0.145)$ & -0.009 & $(0.049)$ \\
\hline SSCI impact factor & 0.025 & $(0.047)$ & -0.023 & $(0.047)$ & 0.189 & $(0.103)$ \\
\hline Proceedings & 0.030 & $(0.032)$ & -0.022 & $(0.029)$ & 0.134 & $(0.055)$ \\
\hline Baseline Dummies & YES & & YES & & YES & \\
\hline Rank Cohort Dummies & YES & & YES & & YES & \\
\hline Observations Number & 4295 & & 3364 & & 1939 & \\
\hline df & 58 & & 58 & & 61 & \\
\hline 11 & -1387 & & -967.4 & & -468.6 & \\
\hline
\end{tabular}

Standard errors in parentheses

*** $\mathrm{p}<0.01,{ }^{* *} \mathrm{p}<0.05,{ }^{*} \mathrm{p}<0.1$ 
Copyright ( 2010 @ the author(s). Discussion papers are in draft form. This discussion paper is distributed for purposes of comment and discussion only. It may not be reproduced without permission of the copyright holder. Copies of working papers are available from the author. 